\title{
Regulation of the 20S Proteasome by a Novel Family of Inhibitory Proteins
}

\author{
Maya A. Olshina, ${ }^{1}$ Galina Arkind, ${ }_{1}^{1}$ Fanindra Kumar Deshmukh,, Irit Fainer, ${ }^{1}$ Mark Taranavsky, Daniel Hayat, \\ Shifra Ben-Dor, ${ }^{2}$ Gili Ben-Nissan, ${ }^{1}$ and Michal Sharon ${ }^{1}$
}

\begin{abstract}
Aims: The protein degradation machinery plays a critical role in the maintenance of cellular homeostasis, preventing the accumulation of damaged or misfolded proteins and controlling the levels of regulatory proteins. The 20S proteasome degradation machinery, which predominates during oxidative stress, is able to cleave any protein with a partially unfolded region, however, uncontrolled degradation of the myriad of potential substrates is improbable. This study aimed to identify and characterize the regulatory mechanism that controls $20 \mathrm{~S}$ proteasome-mediated degradation.

Results: Using a bioinformatic screen based on known 20S proteasome regulators, we have discovered a novel family of 20S proteasome regulators, named catalytic core regulators (CCRs). These regulators share structural and sequence similarities, and coordinate the function of the $20 \mathrm{~S}$ proteasome by affecting the degradation of substrates. The CCRs are involved in the oxidative stress response via Nrf2, organizing into a feed-forward loop regulatory circuit, with some members stabilizing Nrf2, others being induced by Nrf2, and all of them inhibiting the $20 \mathrm{~S}$ proteasome.

Innovation and Conclusion: These data uncover a new family of regulatory proteins that utilize a fine-tuned mechanism to carefully modulate the activity of the $20 \mathrm{~S}$ proteasome, in particular under conditions of oxidative stress, ensuring its proper functioning by controlling the degradative flux. Antioxid. Redox Signal. 32, 636-655.
\end{abstract}

Keywords: 20S proteasome, protein degradation, intrinsically disordered proteins, oxidative stress, Nrf2, ubiquitin-independent degradation

\section{Introduction}

T HE ABILITY TO maintain cellular homeostasis, while being able to rapidly respond to environmental stimuli and stressors, requires a cell to coordinate multiple complex pathways to ensure ongoing cell health and survival (37). To meet the fluctuating needs of the cell, turnover of proteins is necessary to adapt the composition of the proteome as required. The major process through which proteins are degraded involves the ubiquitin/proteasome system, a complicated network of enzymes and degradation machinery that breaks down proteins marked for destruction $(14,26,30)$. This pathway begins with the conjugation of ubiquitin chains to the protein to be degraded via an enzymatic cascade, followed by recognition of the ubiquitin by the $26 \mathrm{~S}$ proteasome

\section{Innovation}

The current understanding of the regulation of the ubiquitin-independent degradation activities of the $20 \mathrm{~S}$ proteasome is limited, and only a small number of regulators have been identified to date. Given the importance of the $20 \mathrm{~S}$ proteasome, in particular during oxidative stress, tight regulation must exist to control its degradative capacity. With our discovery of this novel family of $20 \mathrm{~S}$ proteasome regulatory proteins, the catalytic core regulators, and their connection to the oxidative stress response, we have greatly expanded our understanding of this critical degradation pathway and the fine-tuned mechanisms that control its function.

${ }^{1}$ Department of Biomolecular Sciences, Weizmann Institute of Science, Rehovot, Israel.

${ }^{2}$ Bioinformatics and Biological Computing Unit, Weizmann Institute of Science, Rehovot, Israel. 
complex (54). The $26 \mathrm{~S}$ proteasome comprises a $19 \mathrm{~S}$ regulatory particle, which recognizes ubiquitin tagged substrates, and a $20 \mathrm{~S}$ catalytic core particle, in which substrates are degraded via breakage of peptide bonds. The ATPase activity of several subunits of the $19 \mathrm{~S}$ provides the energy required to unfold the protein substrate and translocate it into the central pore of the 20S, where proteolysis occurs by the activity of its catalytic subunits.

While protein degradation via the ubiquitin/26S proteasome pathway is the predominant mechanism used by the cell to degrade proteins, it has been well established that the $20 \mathrm{~S}$ catalytic core of the proteasome is capable of operating independently of the $19 \mathrm{~S}$ regulatory particle $(4,6,17,18,49$, 50 ). The $20 \mathrm{~S}$ proteasome can degrade protein substrates in a ubiquitin- and ATP-independent manner, by recognizing unfolded or unstructured regions within its substrates, as opposed to the specificity of a ubiquitin tag as required by the $26 \mathrm{~S}$ proteasome $(22,56)$. Proteins can acquire unstructured regions as a result of mutation, acute oxidative stress, and age-related damage. During aging, the proteome accumulates time-inflicted damage from oxidation, irradiation, and mutations, leading to widespread protein dysfunction, which can affect multiple cellular processes (50). Alternatively, proteins can contain intrinsically disordered regions (IDRs), for example, the cell cycle regulators p21 and p27, and tumor suppressors p53 and p73 (21, 34, 70, 74). Beyond complete degradation of unstructured protein substrates, the $20 \mathrm{~S}$ proteasome has also been shown to be responsible for the post-translational processing of certain proteins, generating proteolytic products that display unique roles and functionality compared with their parent proteins $(3,45,46,49,62)$.

Notably, it has been demonstrated that $20 \%$ of all cellular proteins are degraded in an ubiquitin-independent manner by the 20S proteasome (4), and analysis of the human genome has indicated that almost half of all proteins are predicted to contain disordered segments $(21,70)$. Thus, the theoretical substrate pool for the $20 \mathrm{~S}$ proteasome is substantial, even in unstressed cells without widespread damage to proteins. In addition, recent studies have quantified the proportions of the various proteasome complexes across multiple cell types, revealing that the free $20 \mathrm{~S}$ proteasome is consistently the most abundant form of the proteasome in cells $(23,24)$. Furthermore, under conditions of oxidative stress, there is de novo synthesis of $20 \mathrm{~S}$ proteasome subunits and disassembly of the $26 \mathrm{~S}$ proteasome into its $20 \mathrm{~S}$ and $19 \mathrm{~S}$ components, increasing the total amount of free $20 \mathrm{~S}$ proteasome in the cell $(1,31,72)$. The $20 \mathrm{~S}$ proteasome remains catalytically active and has been implicated in the degradation of oxidatively damaged proteins, preventing them from accumulating and causing cytotoxicity and cell death (50). Oxidative stress also leads to the inactivation of ubiquitin conjugating enzymes, disrupting the ubiquitination cascade and thus reducing the flux of proteins through the $26 \mathrm{~S}$ proteasome pathway (58).

The relatively large proportion of free $20 \mathrm{~S}$ proteasomes, in particular under conditions of oxidative stress, is therefore theoretically capable of degrading a significant amount of proteins within the cell, both under normal and stress conditions. Given the broad substrate landscape of the $20 \mathrm{~S}$ proteasome, which encompasses not only damaged proteins but also important regulatory proteins, it is unlikely that $20 \mathrm{~S}$ proteasome-mediated degradation persists in an unregulated manner, as critical imbalances may occur. In addition, the significant increase in damaged proteins during stress that become potentially pathological and prone to aggregation and toxicity and require degradation could overload the $20 \mathrm{~S}$ proteasomes leading to proteasome clogging and consequently dysfunction. Therefore, it is reasonable to assume that the flux of substrate proteins through the 20S proteasome pathway will be tightly regulated (Fig. 1).

While the presence of a regulatory mechanism to control this degradation process is highly likely, to date only two $20 \mathrm{~S}$ proteasome regulators have been identified; $\mathrm{NAD}(\mathrm{P}) \mathrm{H}$ dehydrogenase [quinone] 1 (NQO1) $(2,48)$ and DJ-1 (47). These proteins share multiple similarities in structure and function, such as the presence of a Rossmann fold, their role in the cellular response to oxidative stress, and the ability to "moonlight" as 20 S proteasome inhibitors while being enzymatically active in other cellular pathways (47). Given the cellular implications of improper regulation of the $20 \mathrm{~S}$ proteasome, and the fact that DJ-1 was explored as a potential 20S proteasome regulator based on its similarities to NQO1, we hypothesized that there may exist a broader family of proteins that exhibit these features, and thus may also be able to regulate the $20 \mathrm{~S}$ proteasome.

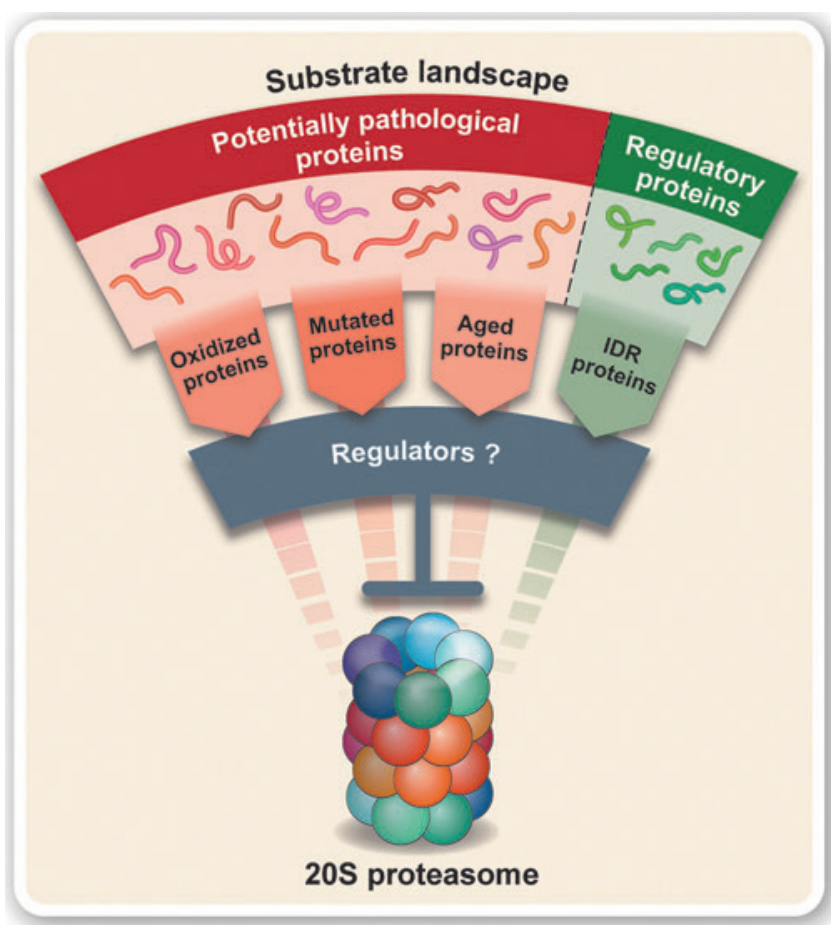

FIG. 1. The flux of substrates into the $20 \mathrm{~S}$ proteasome must be a regulated process. Two main groups of substrates are susceptible to $20 \mathrm{~S}$ degradation. The first consists of proteins that have lost their native structure due to aging, mutations, or oxidative damage. These proteins are prone to aggregation and may lead to cytotoxicity, and therefore should be rapidly removed to prevent cell malfunctions that lead to pathologies, such as neurodegenerative disorders. The second group comprises substrates with unfolded regions as an intrinsic feature of the proteins themselves. Many key regulatory proteins that belong to this group have been shown to be substrates of the $20 \mathrm{~S}$ proteasome. The regulation of the flux of substrates that enter into the $20 \mathrm{~S}$ could prevent proteasome clogging and excessive degradation of essential regulatory proteins. 
Here we performed a bioinformatic screen to identify other proteins with sequence and structural similarities to DJ- 1 and NQO1. This led to the discovery of a family of 17 relatively small proteins of 20-30 kDa, which we named catalytic core regulators (CCRs), that oversee $20 \mathrm{~S}$ proteasome activity. Of the 10 short-listed proteins that were identified and characterized, all were able to inhibit $20 \mathrm{~S}$ proteasome degradation of known substrates, both in vitro and in cells. These protein regulators were able to specifically bind to the $20 \mathrm{~S}$ proteasome, but not the $26 \mathrm{~S}$ proteasome, and affect protein degradation. In addition, we demonstrate that the CCRs organize into a feed-forward regulatory circuit involving the master regulator of the oxidative stress response, Nrf2. Certain CCRs influence the stability of Nrf2, which subsequently upregulates the expression of other CCRs, leading to an overall dampening of $20 \mathrm{~S}$ proteasome-mediated degradation of unfolded protein substrates within the cell. Overall, our results suggest that $20 \mathrm{~S}$ proteasome-mediated degradation is not a simple and random process, but rather a highly CCRregulated and coordinated mechanism.

\section{Results}

\section{$D J-1$ inhibition of the $20 S$ proteasome is conserved across evolution}

Previously, we discovered that DJ-1, the Parkinson's disease-related protein, is a regulator of the 20S proteasome (47). To determine if the inhibitory capacity of DJ-1 is evolutionarily conserved, we began by analyzing its ability to inhibit $20 \mathrm{~S}$ proteasomes purified from three different sources; mammals, yeast, and archaea (Fig. 2A). The IDR containing model substrate $\alpha$-synuclein ( $\alpha$-syn) was used to monitor $20 \mathrm{~S}$ proteasome-mediated degradation over time. Inhibition of the human and yeast $20 \mathrm{~S}$ proteasomes occurred to a similar degree, and despite the vast evolutionary distance, human DJ-1 was also able to reduce the rate of degradation of the archaeal 20S proteasome (Fig. 2A). The reciprocal experiment was also performed, in which DJ-1 homologues from mammals, yeast, and archaea were tested for their ability to inhibit the mammalian 20S proteasome (Fig. 2B). All three DJ-1 homologues were able to inhibit the 20S proteasome, reducing the rate of degradation of $\alpha$-syn over the course of the experiment. Taken together, these results indicate that the inhibition of the $20 \mathrm{~S}$ proteasome by DJ-1 is conserved across evolution, highlighting the essentiality of this cellular process.

\section{Bioinformatic screen identified a new family of CCRs}

The ability of DJ-1 to inhibit 20 S proteasomes from such evolutionarily distant species not only indicates that this process evolved early but it also provides the basis for searching for additional proteins with similar properties. In addition, a homologue of NQO1 from yeast, Lot6, was also shown to interact with and inhibit the $20 \mathrm{~S}$ proteasome, further supporting the view that this is a conserved process (61). Therefore, a bioinformatic approach was used to reveal the sequence and structural similarities of NQO1 and DJ-1, with the rationale that identified features would then be exploited to search for new $20 \mathrm{~S}$ proteasome regulatory candidates. As a first step, a multiple sequence alignment (MSA) of NQO1 and DJ-1 homologues from a wide variety of species was performed (Fig. 2C), revealing a conserved region toward the N-terminus of the proteins. This motif consists of two positively charged residues ( $\mathrm{K}$ or $\mathrm{R}$ ) followed by at least four hydrophobic residues (A, V, I, or L) (Fig. 2D). Both NQO1 and DJ-1 adopt a Rossmann fold, composed of an extended parallel $\beta$-sheet with $\alpha$-helices surrounding both faces to produce a three-layered $\alpha / \beta / \alpha$ sandwich (Fig. 2E). Therefore, the search for new $20 \mathrm{~S}$ proteasome regulatory candidates was restricted to proteins that have been classified as Rossmann fold containing proteins, contain the conserved $\mathrm{N}$-terminal motif, and are less than $100 \mathrm{kDa}$ in size.

The search yielded 17 proteins, including NQO1 and DJ-1, herein referred to as CCRs (Table 1). Interestingly, all of these proteins range in size from 20 to $30 \mathrm{kDa}$, and examination of the literature indicated that many of them are known to be connected to the oxidative stress response in cells, with links to Nrf2 (references listed in Table 1). Included among the potential CCRs are several well-characterized enzymes, such as the quinone reductase enzyme NRH:quinone oxidoreductase 2 (NQO2), which is in the same enzyme family as NQO1, carbonyl reductase 3 (CBR3) and 15hydroxyprostaglandin dehydrogenase (PGDH). Multiple members of the Ras superfamily of proteins are represented, such as NRas, KRas, and HRas, as well as Rho and Rap family proteins. Interestingly, analysis of the tissue-wide protein expression levels of 10 of these putative CCRs demonstrates that some of them display specificity to certain tissues, such as retinoblastoma binding protein 9 (RBBP9) in the oral epithelium and PGDH in the lung, while DJ-1 and RhoA display a significantly more widespread expression profile than that of the other proteins (Supplementary Fig. S1). This hints toward variation in the activities of these proteins, possibly indicating additional significance to the roles of DJ-1 and RhoA.

\section{CCRs inhibit 205 proteasome substrate degradation in vitro}

To determine if any of these candidates are indeed capable of affecting the $20 \mathrm{~S}$ proteasome activity, we selected in addition to NQO1 and DJ-1, eight proteins for analysis: NQO2, CBR3, PGDH, RBBP9, NRas, KRas, HRas, and RhoA. These proteins were expressed, purified, and tested by in vitro degradation assays with purified mammalian 20S proteasomes and two different model substrates, $\alpha$-syn (66) and oxidized calmodulin (OxCaM) (25) (Fig. 3A). MG132 was included as a control for proteasome inhibition. The majority of the CCRs successfully inhibited the degradation of $\alpha$-syn, with the exception of RBBP9 and HRas. However, all of the candidates prevented the degradation of OxCaM. To assess the concentration dependence of the CCRs in inhibiting the $20 \mathrm{~S}$ proteasome, three representative CCRs, NQO2, CBR3, and NRas, were further analyzed using a concentration range of the CCRs, while maintaining constant levels of 20S proteasome and $\alpha$-syn (Supplementary Fig. S2A). While CBR3 and NRas clearly showed concentration-dependent inhibition of the $20 \mathrm{~S}$ proteasome, the inhibition by NQO2 was highly potent, strongly inhibiting degradation even at the lowest concentration tested (Supplementary Fig. S2A). We also performed a representative degradation assay using nanomolar concentrations of CBR3, 20S proteasome, and $\alpha$-syn, to validate the ability of this CCR to inhibit the $20 \mathrm{~S}$ proteasome at these more physiologically relevant concentrations 
A

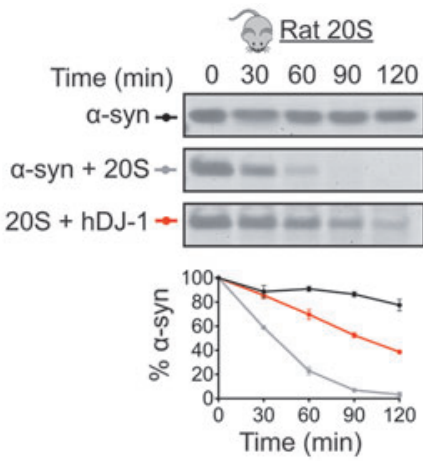

Yeast 20S
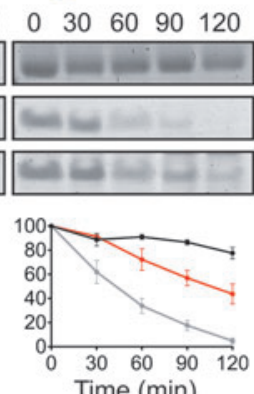

Time (min)
Archaea 20S

$\begin{array}{lllll}0 & 30 & 60 & 90 & 120\end{array}$

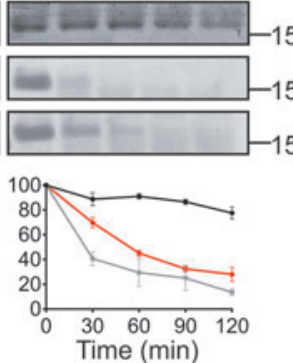

B

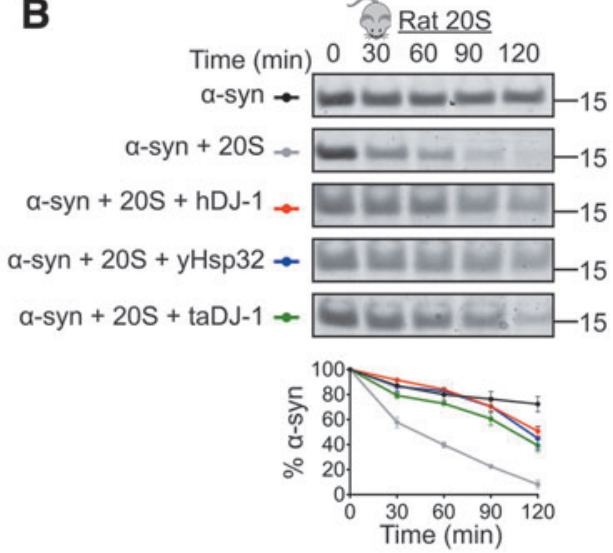

C

tr|Q54QT4|Q54QT4_DICDI tr | J9VPN7 | J9VPN7_CRYNH tr|DONGG6 IDONGG6 PHYIT tr|G3XTP0|G3XTP0_ASPNA sp|Q07923|LOT6_YEAST sp|Q9USJ6|FMNR_SCHPO tr|Q6P0H2|Q6P0H2_DANRE $t r \mid$ H3AHP 9|H3AHP 9_LATCH tr|E1BYW3|E1BYW3 CHICK tr|Q28HD6|Q28HD6_XENTR tr|F7CXV7|F7CXV7_MONDO sp | 264669 | NQO1_MOUSE sp |P15559|NQO1_HUMAN tr $1032 B H 2 \mid 03 \mathrm{ZBH} 2$ BOVIN tr|A0A0C2QBQ7|A0A0C2QBQ7_9CYAN tr|G9AAB9|G9AAB9_RHIFH sp|Q10356|DJ1_SCHPO sp |016228 |DJ12_CAEEL sp|P90994|DJ11_CAEEL tr OOVA 37 IO9VA 37 DROME tr|Q6NTU4/Q6NTU4_XENLA sp|Q5XJ36|PARK7_DANRE sp |Q8UW59|PARK7_CHICK SP|Q99LXO |PARK7 MOUSE sp|Q5E946|PARK7_BOVIN SP|Q99497|PARK7_HUMAN sp|Q04432| HSP 31_YEAST tr|C7LCE7 |C7LCE7_BRUMC tr|K9YAE4 |K9YAE4 HALP7 tr|G7VDP3 |G7VDP3_9CREN tr IC7M356 |C7M356 ACIFD tr|Q9HKX8|Q9HKX8_THEAC tr|F8I381|F8I381_SULAT

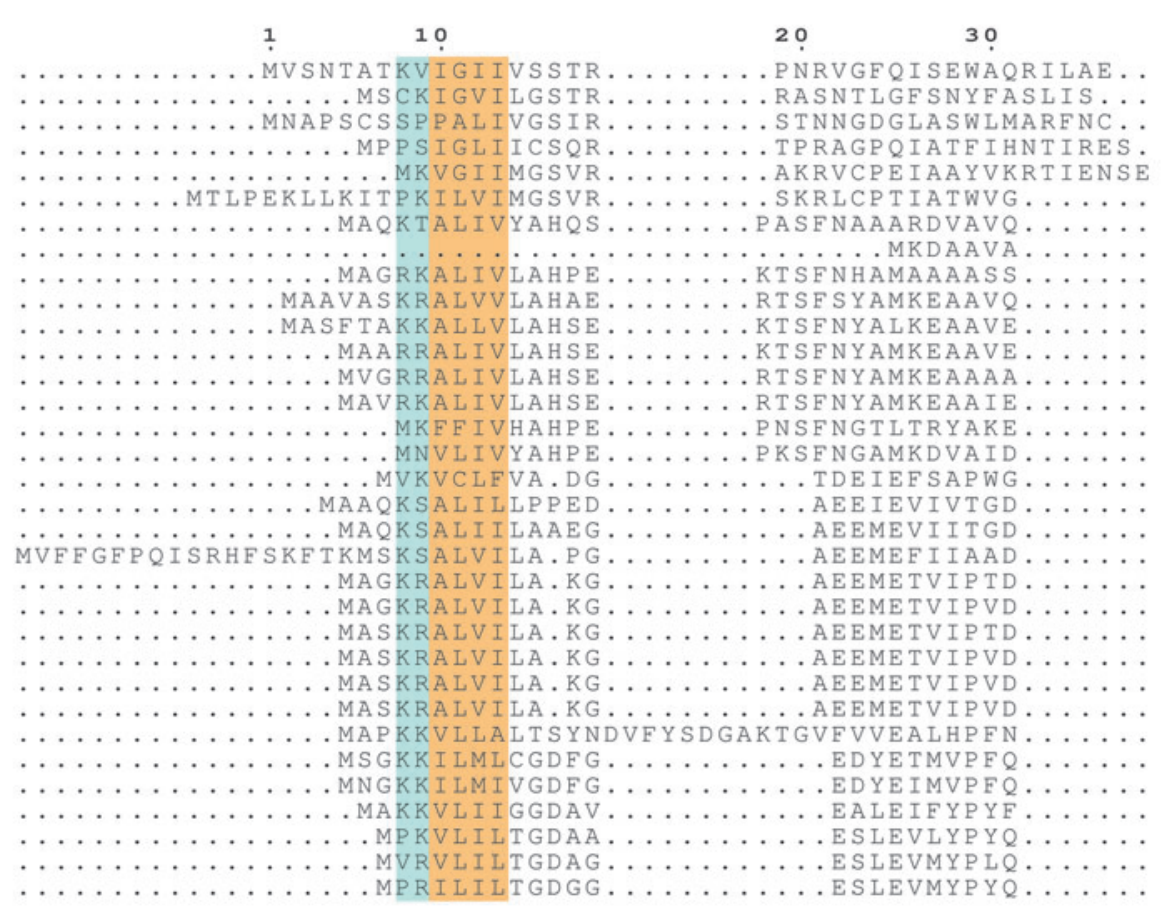

E
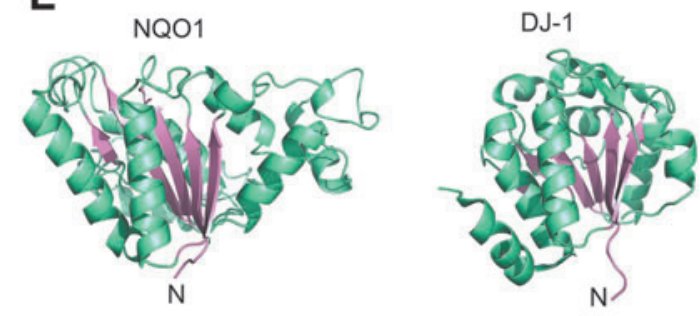

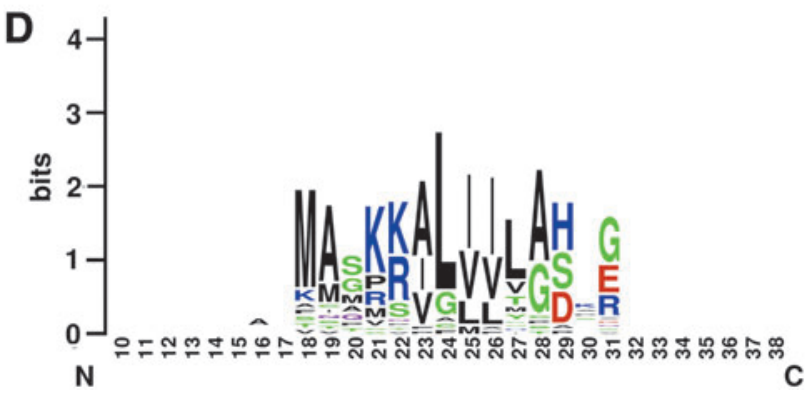

FIG. 2. Evolutionary conservation of the regulatory activity of DJ-1 on the $20 \mathrm{~S}$ proteasome and the discovery of a conserved N-terminal motif. (A) In vitro degradation assays using model substrate $\alpha$-syn were performed using mammalian DJ-1 (Homo sapiens, hDJ-1) with 20S proteasomes from three different sources: mammals (Rattus norvegicus, r20S), yeast (Saccharomyces cerevisiae, y20S), or archaea (Thermoplasma acidophilum, ta20S). (B) In vitro degradation assays were performed using 20S proteasomes from mammals (r20S) with DJ-1 homologues from three different sources: (mammals [hDJ-1], yeast [yHsp32], or archaea [taDJ-1]). Representative Coomassie-stained SDS-PAGE gels with quantification of three independent experiments are shown. The three graphs in (A) were derived from the same set of experiments, and therefore, the quantification of $\alpha$-syn is identical in the graphs. The results are displayed separately for ease of viewing the inhibitory effect of hDJ-1 on each 20 S proteasome. Error bars represent S.E.M. (C) MSA of NQO1 and DJ-1 homologues reveals conservation of two positive residues (highlighted in blue) followed by at least four hydrophobic residues (highlighted in orange) near the N-terminus of the proteins. (D) WebLogo representation of the amino acid conservation near the N-terminus of the MSA. (E) Structures of NQO1 (1D4A.pdb) and DJ-1 (1UCF.pdb) with the central $\beta$-sheet of the Rossmann fold highlighted in pink, and the $\alpha$-helices in green. $\alpha$-syn, $\alpha$-synuclein; MSA, multiple sequence alignment; NQO1, NAD(P)H dehydrogenase [quinone] 1; SDS-PAGE, sodium dodecyl sulfate-polyacrylamide gel electrophoresis; S.E.M., standard error of the mean. 
Table 1. Shortlisted Catalytic Core Regulator Candidates Containing Conserved N-Terminal Motif and a Rossmann Fold

\begin{tabular}{|c|c|c|c|c|c|}
\hline Gene name & Protein name & $N$-terminal sequence & Size, $k D a$ & $P D B$ & Nrf2-Reference \\
\hline$P A R K 7$ & DJ-1 & MASKRALVIL & 20 & 1P5F & $(2,5)$ \\
\hline$N Q O 1$ & NQO1 & MVGRRALIV & 31 & $1 \mathrm{D} 4 \mathrm{~A}$ & $(8)$ \\
\hline NQO2 & NQO2 & MAGKKVLIV & 26 & 1QR2 & (9) \\
\hline CBR3 & CBR3 & MSSCSRVALV & 31 & 2HRB & (1) \\
\hline$H P G D$ & PGDH & MHVNGKVALV & 30 & 2GDZ & (6) \\
\hline$R B B P 9$ & RBBP9 & MASPSKAVIV & 21 & 2QS9 & - \\
\hline$R A S N$ & NRas & MTEYKLVVV & 21 & $3 \mathrm{CON}$ & - \\
\hline$R A S K$ & KRas & MTEYKLVVV & 22 & 4IPK & $(3,7)$ \\
\hline RASH & HRas & MTEYKLVVV & 21 & 4Q21 & (4) \\
\hline RHOA & RhoA & MAAIRKKLVIV & 22 & $1 \mathrm{FTN}$ & (10) \\
\hline$R H O B$ & RhoB & MAAIRKKLVVV & 22 & 2FV8 & - \\
\hline $\mathrm{RHOC}$ & RhoC & MAAIRKKLVIV & 22 & $2 \mathrm{GCN}$ & - \\
\hline$R A P 1 A$ & Rap1A & MREYKLVVL & 21 & $4 \mathrm{KVG}$ & - \\
\hline$R A P 1 B$ & Rap1B & MREYKLVVL & 21 & $3 \mathrm{X} 1 \mathrm{~W}$ & - \\
\hline$R A P 2 A$ & Rap2A & MREYKVVVL & 21 & $1 \mathrm{KA} 0$ & - \\
\hline$E T F B$ & ETFB & MAELRVLVAV & 28 & $1 \mathrm{EFV}$ & - \\
\hline PGAM1 & PGAM1 & MAAYKLVLI & 29 & 4GPI & - \\
\hline
\end{tabular}

Relevant references linking between the transcription factor Nrf2 and a specific CCR are indicated.

CCR, catalytic core regulator.

(Supplementary Fig. S2B). Taken together, these results indicate that the CCRs are capable of inhibiting protein degradation by the $20 \mathrm{~S}$ proteasome in vitro, with an element of substrate specificity demonstrated for HRas and RBBP9.

To clarify whether the inhibition is a result of competitive inhibition, that is, the CCRs themselves are being degraded by the $20 \mathrm{~S}$ proteasome in preference to the model substrates, each CCR was analyzed by in vitro degradation assay with 20S proteasome in the absence of a substrate (Supplementary Fig. S3A). Quantification of the amount of CCRs remaining over the course of the assay indicated that they themselves are stable, and are therefore not acting as competitive substrates (Supplementary Fig. S3B).

We continued by examining whether the CCRs can affect the enzymatic activity of the $20 \mathrm{~S}$ proteasome using a fluorogenic peptidase activity assay (Fig. 3B). Compared with MG132, which drastically reduced the proteolytic activity of the $20 \mathrm{~S}$ proteasome, several of the CCRs behaved like DJ-1 (47) and showed an insignificant effect on peptide degradation. However, CBR3 and RBBP9 reduced the proteolytic activity by about half, while NQO1 and PGDH showed the most significant inhibition. To determine the concentration dependence of the CCRs on their ability to inhibit peptide degradation, representative CCRs that inhibited (NQO1, CBR3) or did not inhibit (NQO2, NRas) peptide degradation were selected and tested using a concentration range of the CCRs (Supplementary Fig. S4). While the inhibitory CCRs displayed a clear concentration dependence in their inhibition, the peptide-noninhibitory CCRs did not inhibit at any concentration tested. While there are differences in the capacity of the CCRs to prevent peptide degradation, they are not able to completely block degradation, as was observed for MG132. This indicates that they do not deactivate the catalytic sites of the proteasome, but rather they act using another regulatory mechanism. Whether the CCRs prevent protein degradation by masking the entrance to the proteasome or by an allosteric mechanism remains to be determined.
To address whether the CCR inhibitory capacity on the $20 \mathrm{~S}$ proteasome is conserved across evolution, as was demonstrated for DJ-1 (Fig. 2), we selected CBR3 as a representative CCR and analyzed its effect on the degradation of $\alpha$-syn by yeast and archaeal $20 \mathrm{~S}$ proteasomes (Supplementary Fig. S5A, B). Human CBR3 inhibited degradation by both proteasomes, indicating that like DJ-1, inhibition of the $20 \mathrm{~S}$ proteasome by the CCR family is conserved across evolution. This observation further strengthens the possibility of conservation of function across CCRs from evolutionarily distant species (Supplementary Fig. S5C).

\section{CCRs preferentially bind to the 205 proteasome over the 265 proteasome to inhibit substrate degradation}

The ability of the CCRs to inhibit protein degradation could be due to either direct interactions with the 20S proteasome or sequestration of the substrate away from the proteasome by forming a stable complex with the regulator. Previous experiments with NQO1 and DJ-1 revealed that they did not interact with the substrate itself but rather physically bound to the $20 \mathrm{~S}$ proteasome and inhibited its activity directly $(47,48)$. We therefore utilized this native mass spectrometry approach and started by analyzing the interaction between the CCRs and $\alpha$-syn (Supplementary Fig. S6). $\alpha$-syn was incubated with each of the CCRs and their native mass spectra were analyzed. No larger complexes formed by the CCRs and $\alpha$-syn were detected, suggesting that the inhibition of protein degradation does not occur by competitive inhibition via substrate sequestration. The inhibition of protein degradation is therefore likely mediated by direct binding of the CCRs to the 20S proteasome. To test this, each of the CCRs was incubated with 20S proteasome, and tandem mass spectrometry (MS/MS) was used to detect binding. MS/MS involves three stages, beginning with the acquisition of a native MS spectrum of the intact protein complex in the protein mixture. This allows for the identification of the $20 \mathrm{~S}$ proteasome in the high $\mathrm{m} / \mathrm{z}$ range, as well as 
A

FIG. 3. CCRs inhibit the degradation of partially folded proteins by the $20 \mathrm{~S}$ proteasome. (A) In vitro degradation assays of each CCR with substrates (Sub) $\alpha$-syn (left) or OxCaM (right). MG132 was included as a control for $20 \mathrm{~S}$ proteasome inhibition. Panels display Coomassie-stained SDS-PAGE, unless labeled with an asterisk, which denotes immunoblots using the anti-calmodulin antibody for those CCRs that are the same size as the substrate: RBBP9, NRas, KRas, HRas, and RhoA. Quantification of three independent experiments is displayed, error bars represent S.E.M. (B) Peptidase activity of $20 \mathrm{~S}$ proteasomes in the presence of CCRs or MG132 was monitored using the fluorogenic peptide substrate suc-LLVY-AMC. Error bars represent S.E.M. of three independent experiments. CCR, catalytic core regulator; OxCaM, oxidized calmodulin; RBBP9, retinoblastoma binding protein 9 .

B
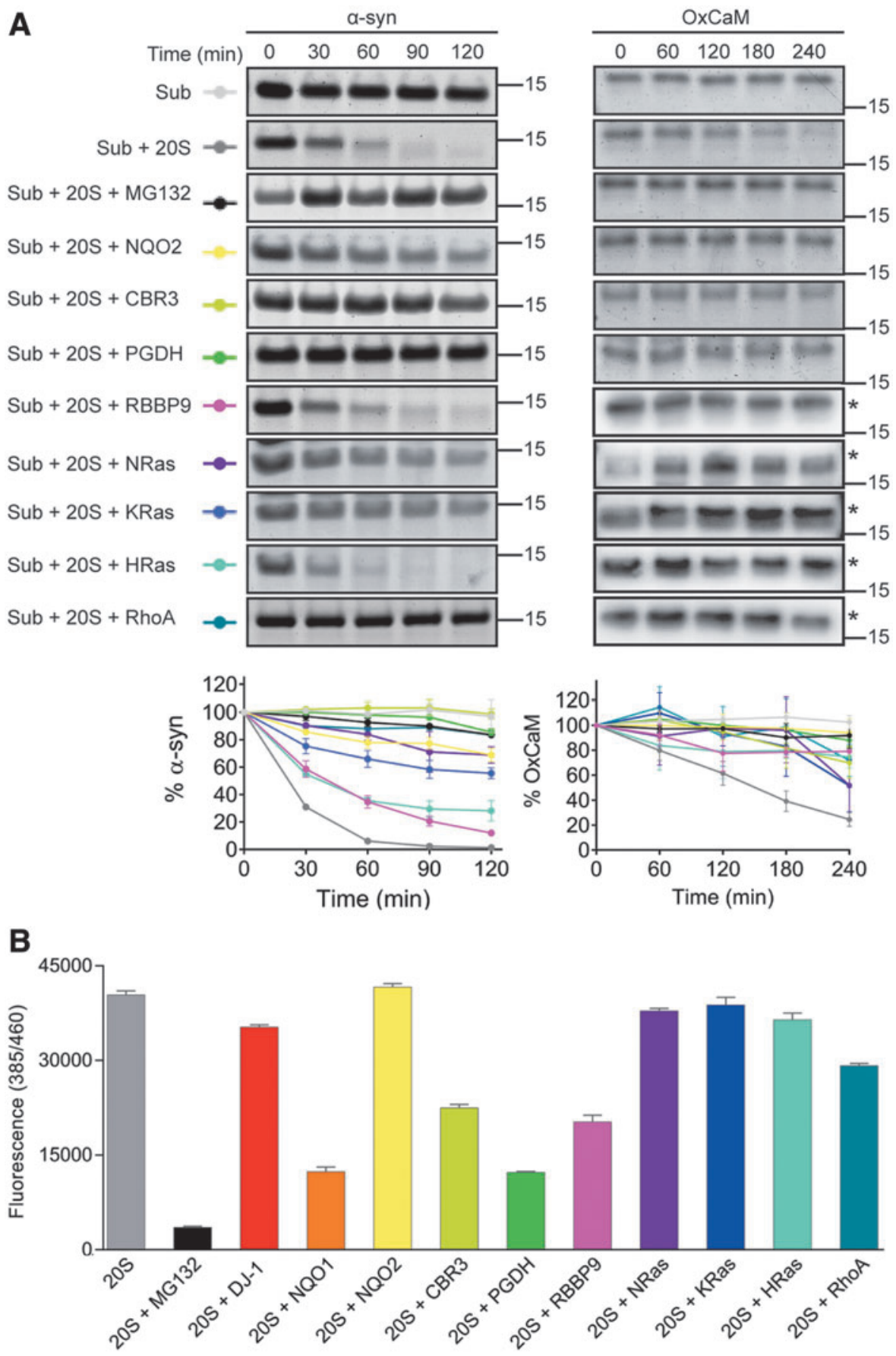

free CCR in the low $m / z$ range. The peak series corresponding to the $20 \mathrm{~S}$ proteasome complex is then isolated, allowing for specific selection of the $20 \mathrm{~S}$ proteasome and its associated proteins, and not free CCR that remains unbound. The isolated complexes are subjected to high collision energies, leading to dissociation of any bound proteins as well as individual subunits of the $20 \mathrm{~S}$ proteasome. These dissociated monomeric subunits and proteins can be detected in the low $\mathrm{m} / \mathrm{z}$ range of the spectrum, and mass assignment allows for the identification of known 20S subunits, as well as CCRs that were bound to the $20 \mathrm{~S}$ proteasome (Fig. 4A). For each of the samples containing the CCRs, a unique series of peaks corresponding in size to the predicted molecular weight of the specific CCR were identified, that were not found in the spectrum for the 20S proteasome alone, alongside peak series corresponding to known 20S proteasome subunits (Fig. 4B$\mathrm{K}$ and Supplementary Table S1). By extrapolation, we can therefore conclude that before the MS/MS analysis, the examined CCRs bound directly to the $20 \mathrm{~S}$ proteasome to regulate its function.

To determine whether this binding occurs in cells, and is specific for the $20 \mathrm{~S}$ proteasome, or if the CCRs can also bind to the $26 \mathrm{~S}$ proteasome, immunoprecipitation (IP) experiments were performed using HEK293T cells stably expressing the $20 \mathrm{~S}$ proteasome $\beta_{4}$ subunit with a FLAG-tag on the C-terminus. Four representative CCRs (NQO2, PGDH, 
NRas, and RhoA) were selected for the analysis. Each of these CCRs, containing a C-terminal HA-tag, was transiently overexpressed before lysis and IP to aid in the efficiency of the pull down. Whole cell lysates were IP'd with anti-FLAG, anti-HA, or anti-Rpn2 (a subunit of the 19S regulatory particle of the $26 \mathrm{~S}$ proteasome) antibodies, to pull down the $20 \mathrm{~S}$ proteasome, the CCRs, or the $26 \mathrm{~S}$ proteasome, respectively. A control IP using uncoupled Protein $\mathrm{G}$ beads was performed in parallel to ascertain the background levels of the proteins binding to the beads during the IP. Bound proteins were then analyzed by Western blotting with anti-PSMA1 (20S proteasome $\alpha_{1}$ subunit), anti-Rpn2 (19S subunit), and anti-CCR/ HA antibodies (Fig. 4L, N, P, R, and Supplementary Fig. S7). Quantification of the levels of the CCRs being pulled down with the $20 \mathrm{~S}$ proteasome in the FLAG IP revealed a significant increase in the amount of CCRs binding to the $20 \mathrm{~S}$ proteasome, compared with the Protein G control (Fig. 4M, $\mathrm{O}, \mathrm{Q}, \mathrm{S}$-left panels). This interaction was confirmed in the reciprocal IP, where the amount of $20 \mathrm{~S}$ proteasome being pulled down with the CCRs in the HA IP is significantly increased compared with the Protein G control (Fig. 4M, O, $\mathrm{Q}, \mathrm{S}$-right panels). Of note, the interaction between RhoA and the 20S proteasome was detectable only after exposure of the cells to oxidative stress, likely due to the increased levels of free 20S proteasome under these conditions, as discussed earlier. Binding of the CCRs to the 26S proteasome (Rpn2) only occurred at low levels in both the HA and Rpn2 IPs, indicating a preference for CCR binding to the 20S proteasome, or to singly capped $26 \mathrm{~S}$ proteasomes. Taken together, these results establish that the CCRs specifically bind to the $20 \mathrm{~S}$ proteasome in cells.

\section{CCRs stabilize the cellular levels of 205 proteasome substrates}

We were motivated to examine whether our in vitro observations, revealing the CCR ability to bind to the $20 \mathrm{~S}$ proteasome and to prevent substrate degradation, are also relevant in a cellular context. To explore this, we over- expressed three representative CCRs (NQO2, CBR3, and PGDH), alongside green fluorescent protein (GFP) as a control, in HEK293T cells and measured the effect on known 20S proteasome substrates, $\alpha$-syn and p53 (2) (Fig. 5A-C and Supplementary Fig. S8A-C). The cellular levels of both $\alpha-$ syn and p53 increased significantly when the CCRs were overexpressed compared with GFP. These data indicate that the $20 \mathrm{~S}$ proteasome is being inhibited by the increased levels of CCRs in the cells, leading to reduced degradation of substrates and their consequent accumulation.

To determine if the effect of CCR inhibition of the 20S proteasome is relevant to other known substrates, we followed the levels of a cell cycle regulator, p21, an IDP that has been previously shown to be a substrate of the $20 \mathrm{~S}$ proteasome $(11,12,38)$. However, analysis of this protein is complicated by two factors. First, evidence has shown that p21 can be ubiquitinated and degraded both by the $26 \mathrm{~S}$ proteasome and the $20 \mathrm{~S}$ proteasome (8), making it challenging to differentiate by which route $\mathrm{p} 21$ is being degraded and therefore which degradation pathway is affected by any treatment or intervention. Second, the basal levels of p21 are low across most of the cell cycle, with the exception of enrichment at the G1/S checkpoint (74), leading to difficulties in the detection of p21 at sufficient levels for analysis. Therefore, to follow changes in the levels of p21, we used the mouse fibroblast cell line, A31N-ts20 BALB/c, which contains a temperature-sensitive mutant of the E1 ubiquitin activating enzyme (55). Incubation of these cells at the permissive temperate of $32^{\circ} \mathrm{C}$ allows normal cell growth. Upon transfer of the cells to the restrictive temperature of $39^{\circ} \mathrm{C}$, the E1 enzyme is deactivated, and the ubiquitination cascade is subsequently affected. The reduction in ubiquitination levels allows for the accumulation of proteins such as $\mathrm{p} 21$, which is normally ubiquitinated and degraded. Under these conditions, degradation by the $26 \mathrm{~S}$ proteasome is attenuated, while leaving the $20 \mathrm{~S}$ proteasome degradation route unaffected. We transiently overexpressed the same three CCRs (NQO2, CBR3, and $\mathrm{PGDH}$ ) in $\mathrm{A} 31 \mathrm{~N}-\mathrm{ts} 20 \mathrm{BALB} / \mathrm{c}$ cells, followed by $24 \mathrm{~h}$ of growth at either $32^{\circ} \mathrm{C}$ or $39^{\circ} \mathrm{C}$ (Fig. $5 \mathrm{D}-\mathrm{F}$ and

FIG. 4. CCRs physically bind the 20S proteasome both in vitro and in cells. $20 \mathrm{~S}$ proteasomes alone or in the presence of CCRs were analyzed by native mass spectrometry to determine the binding status of the CCRs to the 20S proteasome. (A) Schematic of native MS methodology, in which 20S proteasomes are incubated with CCRs, leading to a mixed population of free $20 \mathrm{~S}$ proteasomes, free CCRs, and CCR-bound 20S proteasome complexes. The complexes are isolated (highlighted in pink) and subjected to increased collision energy. This leads to the dissociation and detection of 20S proteasome subunits and bound CCRs (indicated by the box), leaving a stripped $20 \mathrm{~S}$ proteasome lacking bound CCRs and several subunits. (B) Native MS1 spectrum of $20 \mathrm{~S}$ proteasomes. Highlighted peaks were isolated and subjected to increased collision energy. (C) MS/MS spectrum of $20 \mathrm{~S}$ proteasome, and the charge series of individual dissociated 20S subunits were identified (white, gray, black balls). (D-K) 20S proteasomes were preincubated with CCRs, followed by MS/MS analysis to identify CCR binding. Unique charge series corresponding in size to the monomeric size of each of the CCRs was detected (colored balls), indicating that CCRs physically bind to the 20S proteasome. For predicted and measured masses of 20S proteasome subunits and CCRs, see Supplementary Table S1. For cellular experiments, HA-tagged (L, M) NQO2, (N, O) PGDH, (P, Q) NRas, and (R, S) RhoA were overexpressed in HEK293T cells stably expressing FLAG-tagged $\beta 4$-subunit of the 20S proteasome. For RhoA (R, S), cells were exposed to $100 \mu \mathrm{M}$ DEM for $48 \mathrm{~h}$ before collection and lysis. Lysates were subjected to IP using anti-FLAGaffinity gel, anti-HA or anti-Rpn2 antibodies, or uncoupled Protein G beads as a control. Total starting lysate (L), UB, and IP samples were analyzed by Western blot using anti-20S, anti-HA, or anti-Rpn2 antibodies. Bands corresponding to HA (i.e., CCRs) in the FLAG (20S) IP and FLAG (20S) in the HA IP were quantified and compared with their Protein G equivalents. Each of the CCRs was significantly enriched in the FLAG (20S) IP demonstrating that the CCRs bind to the 20S proteasome. The reciprocal IP with anti-HA confirmed this interaction, with significant enrichment of the FLAG (20S) bands. Quantifications demonstrate the average of $(\mathbf{M}, \mathbf{O}, \mathbf{S})$ four or $(\mathbf{Q})$ five independent experiments. Band intensity measurements were subjected to Student's $t$-test analysis, $* p<0.05, * * p<0.01$, $* * * p<0.001$, and $* * * * p<0.0001$. Error bars represent S.E.M. DEM, diethylmaleate; IP, immunoprecipitation; MS/MS, tandem mass spectrometry; NQO2, NRH:quinone oxidoreductase 2; PGDH, 15-hydroxyprostaglandin dehydrogenase; UB, unbound proteins. 


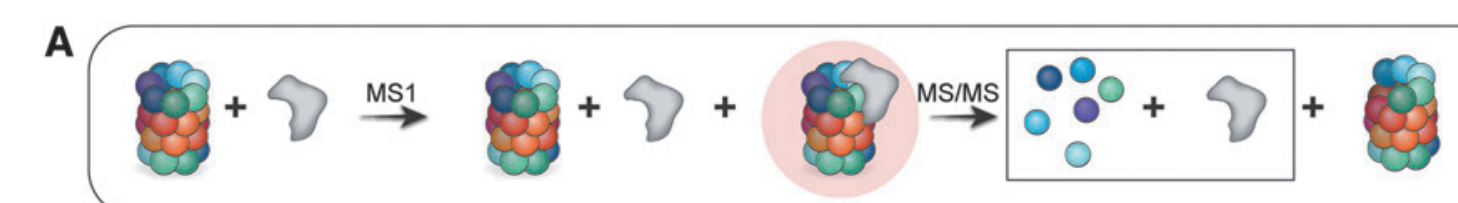

B
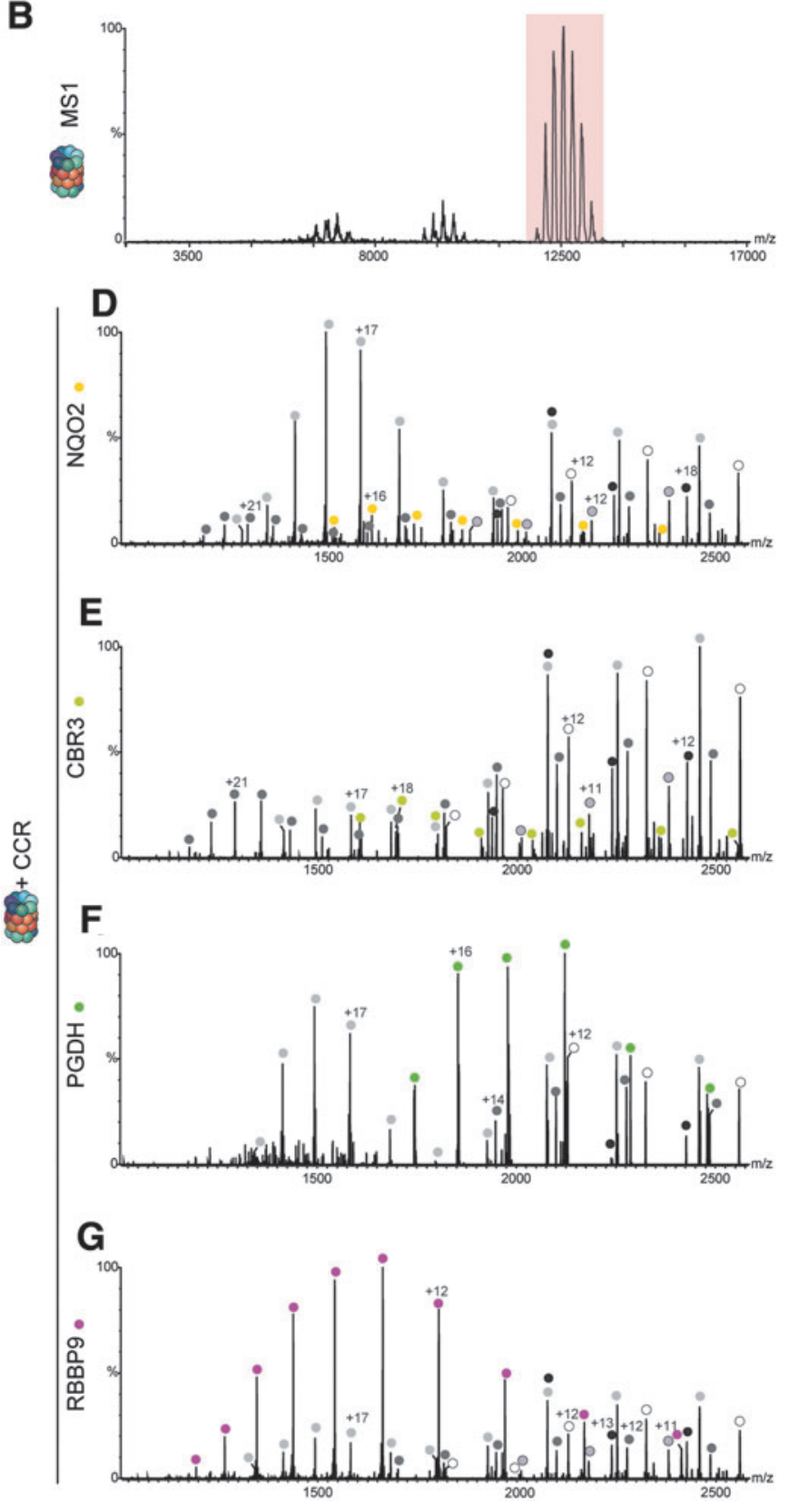

C
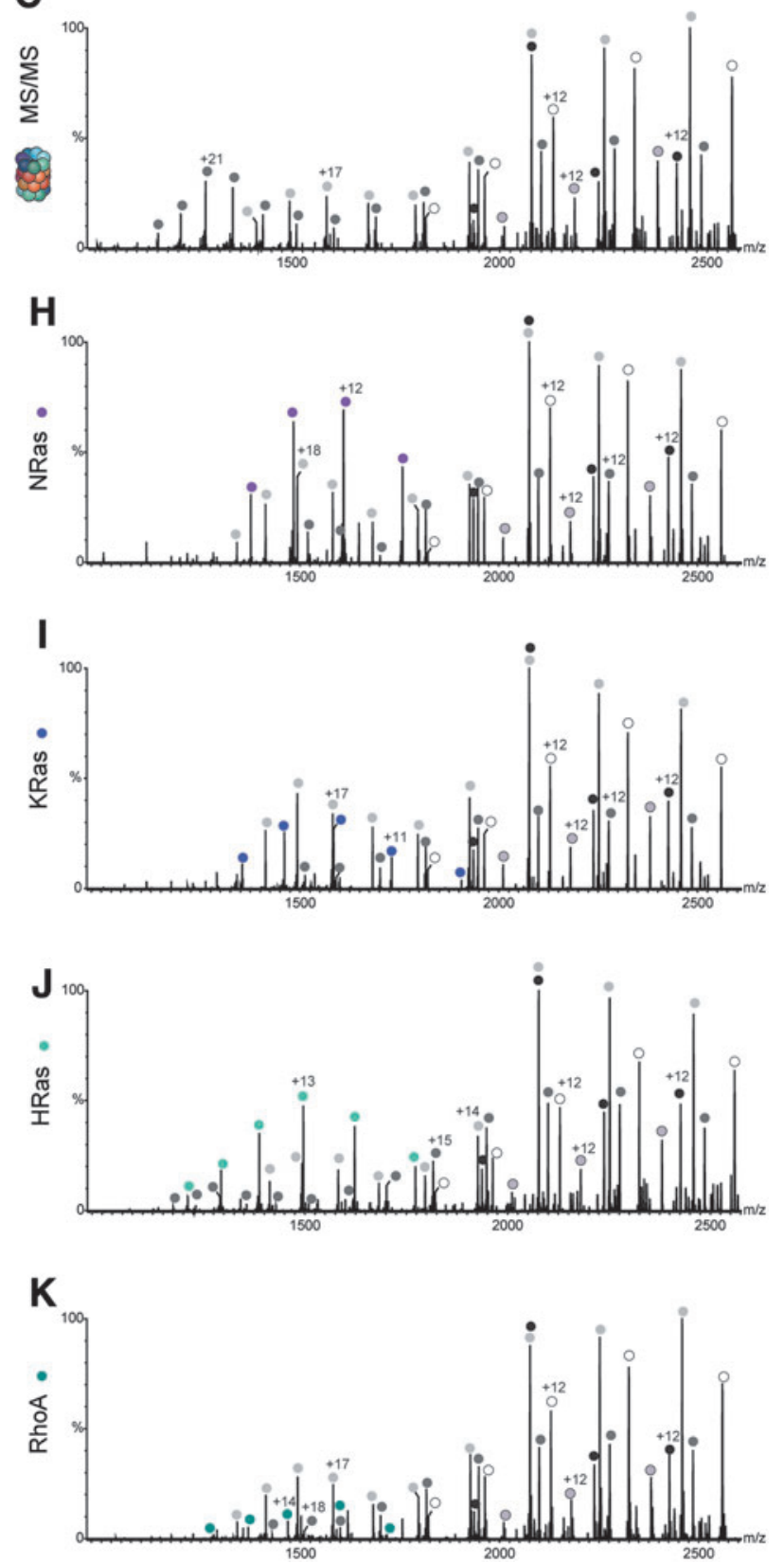

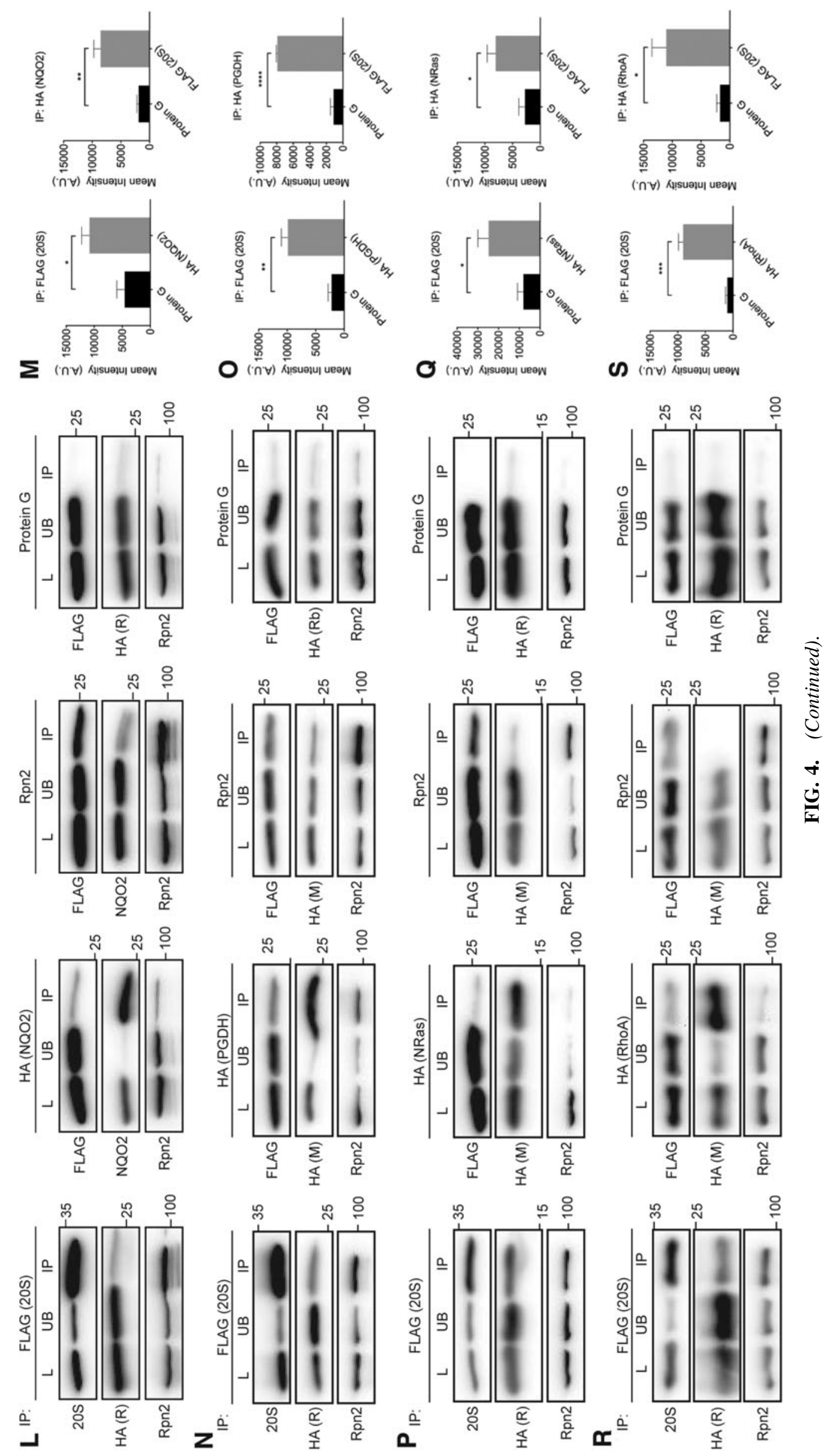

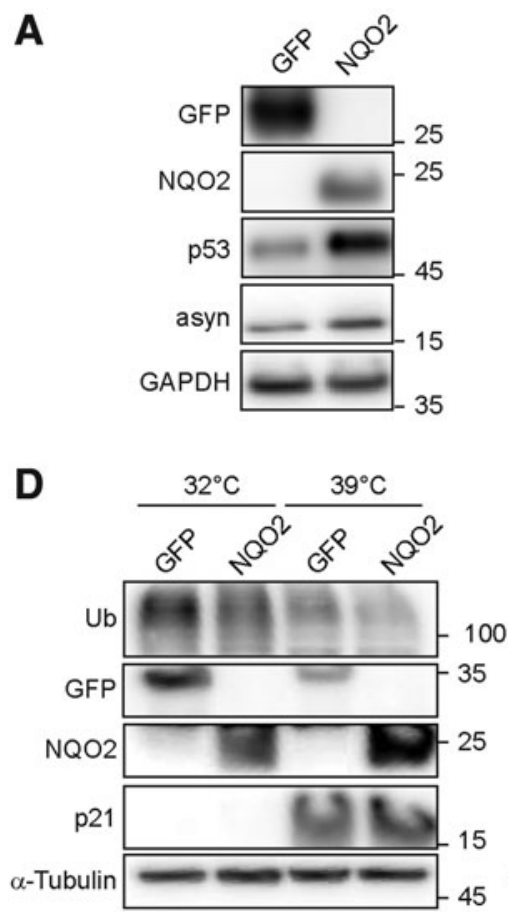

B
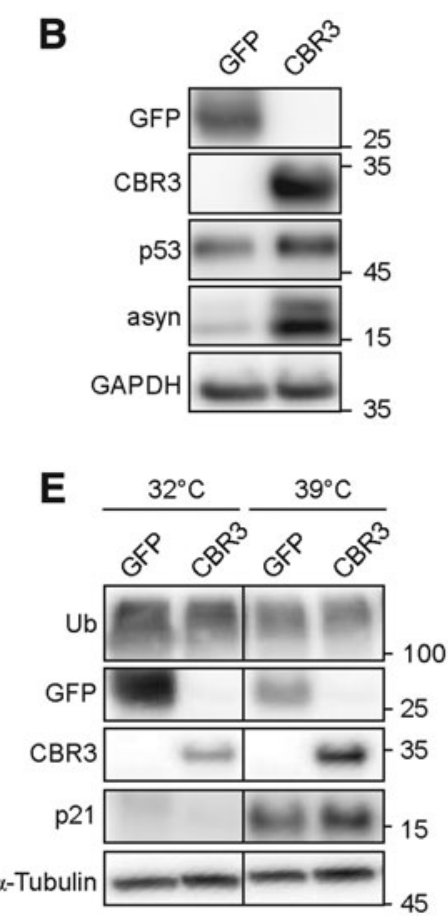

C
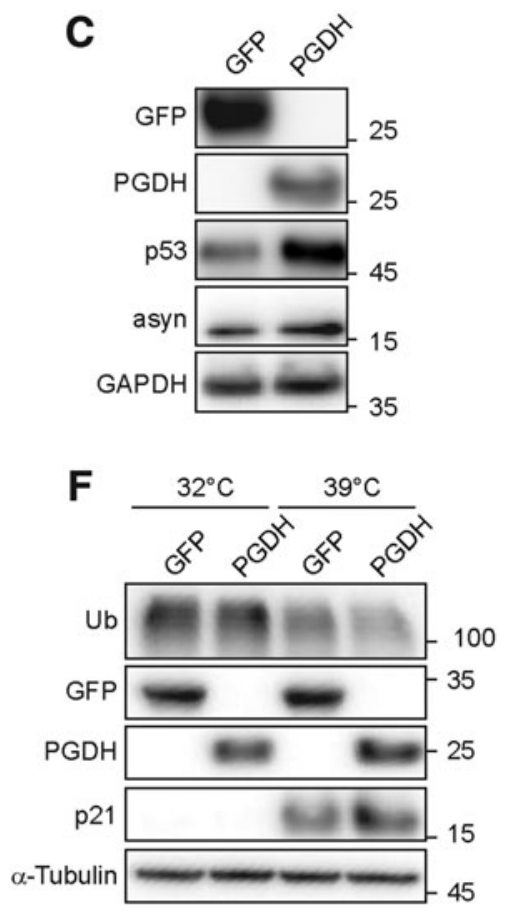

FIG. 5. Overexpression of CCRs stabilizes the cellular levels of $20 \mathrm{~S}$ proteasome substrates. Representative CCRs NQO2, CBR3, and PGDH were transiently overexpressed in HEK293T cells (A-C, respectively) and A31N cells (D-F, respectively). GFP was transfected in parallel as a control in all experiments. The levels of 20S proteasome substrates $\alpha$-syn and p53 in HEK293T cells, and p21 in A31N cells were detected by Western blot. p21 was only detected at the restrictive temperature of $39^{\circ} \mathrm{C}$ in $\mathrm{A} 31 \mathrm{~N}$ cells due to inactivation of the ubiquitination cascade, as seen by the reduction in ubiquitin conjugates compared with $32^{\circ} \mathrm{C}$. In all cases, the levels of the substrates were enriched when the CCRs were overexpressed compared with GFP, indicating inhibition of $20 \mathrm{~S}$ proteasome-mediated degradation. Results are representative of three independent experiments. CBR3, carbonyl reductase 3.

Supplementary Fig. S8D-F). At the restrictive temperature, we clearly see a reduction in ubiquitin conjugate levels, and appearance of $\mathrm{p} 21$, due to the loss of the ubiquitination cascade. Compared with the GFP control, p21 levels are enriched when the CCRs are overexpressed. This stabilization of p21 levels is likely due to the specific inhibition of the $20 \mathrm{~S}$ proteasome degradation pathway by the CCRs. Altogether, these data demonstrate that the CCRs influence the cellular levels of $20 \mathrm{~S}$ proteasome substrates.

\section{CCRs and Nrf2 form a robust regulatory circuit during oxidative stress}

Previous research demonstrated that NQO1 and DJ-1 form a feedback loop with the transcription factor Nrf 2 in response to oxidative stress to regulate the activity of the $20 \mathrm{~S}$ proteasome (47). DJ-1 was shown to stabilize the levels of Nrf2 (15), in turn inducing the expression of NQO1 and subunits of the 20S proteasome (47). In parallel, DJ-1 and NQO1 both inhibit the $20 \mathrm{~S}$ proteasome, thus providing a delicate balance between increased $20 \mathrm{~S}$ proteasome levels during oxidative stress, and appropriate control of $20 \mathrm{~S}$ proteasome degradation (47). Many of the newly discovered CCRs have been shown to be linked to Nrf2 either as downstream transcriptional targets or upstream factors that influence stability (Table 1) $(13,19,28,60,65,71,75)$. To determine the status of each CCR during the Nrf2 response to oxidative stress, we downregulated the levels of Nrf2 followed by induction of oxidative stress using diethylmaleate (DEM), a compound that depletes glutathione, leading to the accumulation of reactive oxygen species (Fig. 6A, B, and Supplementary Figs. S9A and S10). As expected, induction of oxidative stress led to nuclear translocation of Nrf2 accompanied by its accumulation. Quantification of the levels of the CCRs led us to classify them into three groups, depending on their response to oxidative stress and Nrf2 silencing (Fig. 6C-E). The first group is the inducible Nrf2 responders: NQO2 and CBR3 responded in the same manner as NQO1, with increasing protein levels over the time-course of oxidative stress, which were reduced when Nrf2 was silenced (Fig. 6C). The second group is the basal Nrf2 responders, comprising only NRas, which did not show a significant increase during oxidative stress, however, when Nrf2 was silenced its levels were significantly reduced (Fig. 6D). This observation is supported by previous studies showing that Nrf2 can activate the transcription of certain genes under basal conditions, as opposed to under oxidative stress (41). This is the first reported data revealing transcriptional regulation of NRas by Nrf2, hinting toward a potentially important influence of Nrf2 on the Ras family signaling pathways.

The CCRs (along with DJ-1) that did not increase during oxidative stress, or decrease when Nrf2 was silenced, and are thus classified as nonresponders, were PGDH, RBBP9, and RhoA (Fig. 6E). Interestingly, the presence of DJ-1 and RhoA in this group adds additional significance to the tissuewide expression data (Supplementary Fig. S1), which demonstrated that these two CCRs show the highest and most widespread protein expression levels of all the CCRs 

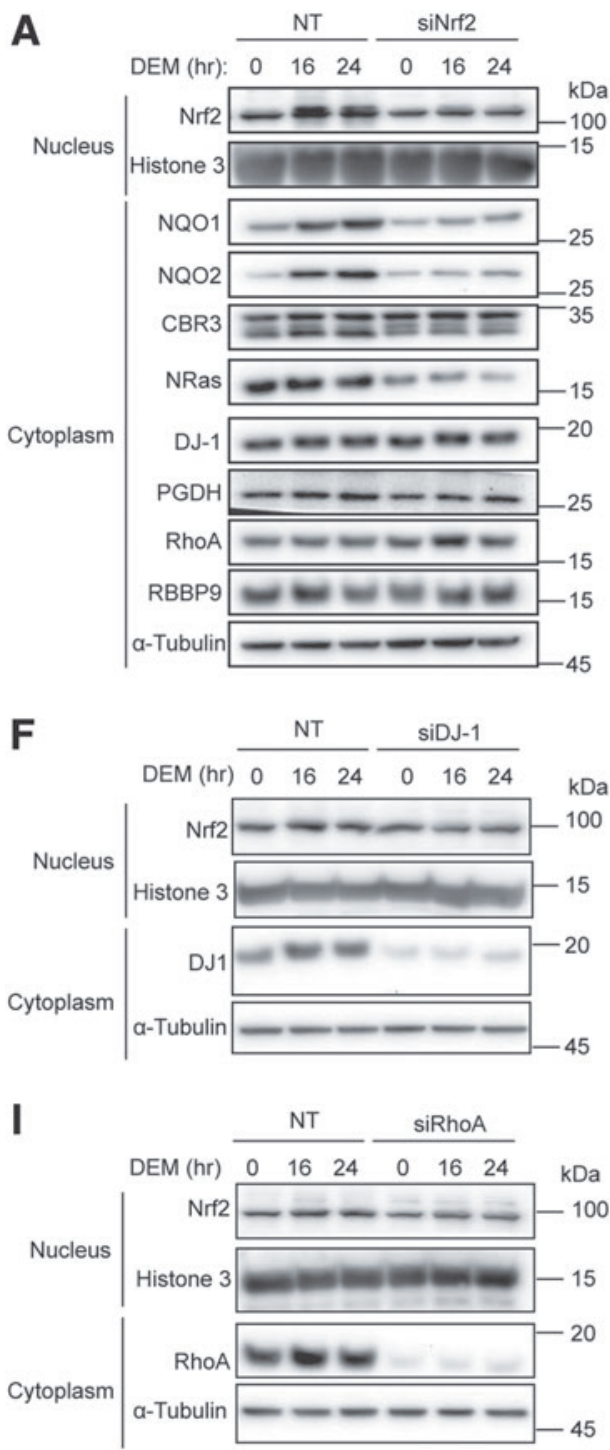

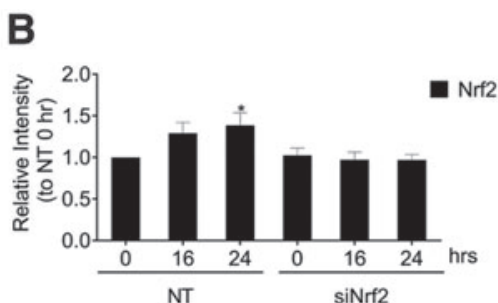

C
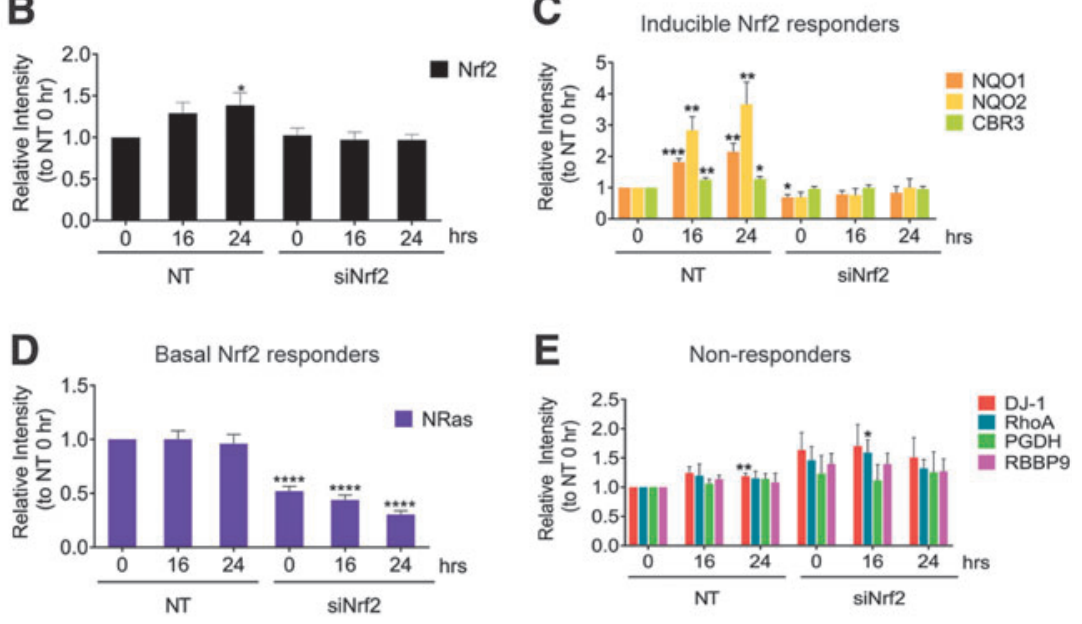

G

H

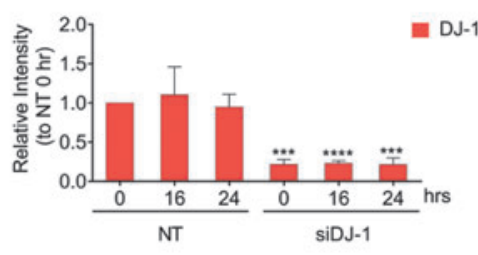

$\mathbf{J}$

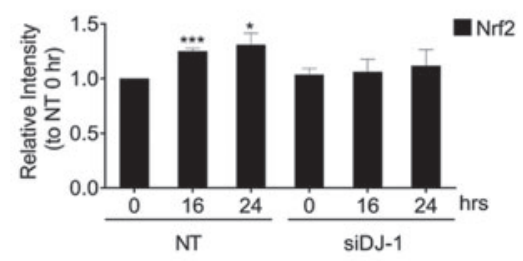

$\mathbf{K}$

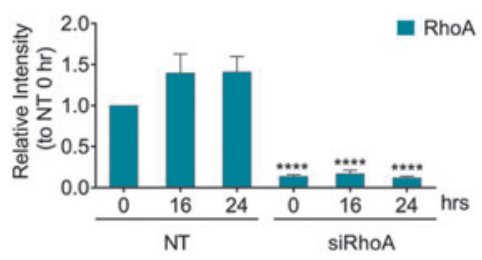

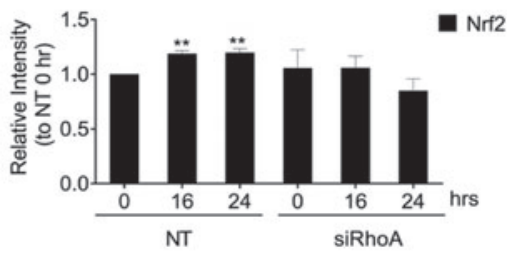

FIG. 6. CCRs are involved in the oxidative stress response via the Nrf2 pathway. (A) MCF10A cells were transiently transfected with either nontargeting siRNA (NT) or siRNA against Nrf2 (NFE2L2). Forty-eight hours post-transfection, cells were exposed to $150 \mu M$ DEM to induce oxidative stress for 0,16 , or $24 \mathrm{~h}$. Cells were collected, fractionated into cytoplasmic and nuclear fractions, and analyzed by Western blot to assess the levels of Nrf2 and the CCRs. (B-E) Changes in the levels of Nrf2 and the CCRs relative to NT at $0 \mathrm{~h}$ were quantified from four independent experiments. The CCRs were categorized into three groups based on their response to Nrf2 silencing; (C) inducible Nrf2 responders (NQO1, NQO2, and CBR3), (D) basal Nrf2 responders (NRas), and (E) nonresponders (DJ-1, RhoA, PGDH, and RBBP9). The CCRs DJ-1 and RhoA from the nonresponder group were transiently silenced in MCF10A cells for $48 \mathrm{~h}$, followed by exposure to DEM for 0,16 , or $24 \mathrm{~h}$. Cells were collected, fractionated into cytoplasmic and nuclear fractions, and analyzed by Western blot to assess the levels of Nrf2 during (F) DJ-1 and (I) RhoA silencing. Changes in the levels of (G) DJ-1 and (H) Nrf2 during DJ-1 silencing, and (J) RhoA and (K) Nrf2 during RhoA silencing, demonstrates that these two CCRs influence the translocation of Nrf2 to the nucleus during oxidative stress. Altogether, these data indicate that the CCRs organize into a regulatory loop with $\mathrm{Nrf} 2$, providing tight control over the $20 \mathrm{~S}$ proteasome during oxidative stress. Quantification relative to NT at $0 \mathrm{~h}$ was performed from three independent experiments. Band intensity measurements were subjected to Student's $t$-test analysis, $* p<0.05, * * p<0.01, * * * p<0.001$, and $* * * * p<0.0001$. Error bars represent S.E.M.

analyzed. Given that DJ-1 was shown to stabilize Nrf2 (47), there could be a correlation between widespread protein expression and Nrf2 stabilization. To determine if RhoA can stabilize the levels of Nrf2 in the same manner as DJ-1, we silenced these CCRs and monitored the levels of Nrf2 in the nucleus during oxidative stress. As expected, silencing of DJ-1 prevented an increase in Nrf2 in the nucleus during oxidative stress (Fig. 6F-H and Supplementary Figs. S9B and
S10), in accordance with our previous results (47). Reducing the levels of RhoA also significantly weakened the response of Nrf2 to oxidative stress, preventing nuclear accumulation of Nrf2 (Fig. 6I-K and Supplementary Figs. S9C and S10). These results indicate that DJ-1 and RhoA act upstream of Nrf2 to stabilize its levels and ensure appropriate nuclear accumulation during oxidative stress, enabling the oxidative stress response to occur. 


\section{Discussion}

This study describes the discovery of a novel family of $20 \mathrm{~S}$ proteasome regulators, the CCRs. We have demonstrated that a robust link exists between Nrf2 and the CCRs, specifically regulating the $20 \mathrm{~S}$ proteasome by physically binding, and attenuating, substrate degradation. The expression of many of the CCRs is controlled by Nrf2, which in turn is itself stabilized by at least two members of the CCR family. Together, this creates a feed-forward loop of regulation (42), within which the $20 \mathrm{~S}$ proteasome is upregulated by Nrf2 and simultaneously inhibited by the CCRs (Fig. 7). This enables a pulse of activity and rapid shutdown during the oxidative stress response, allowing degradation of damaged proteins while protecting the levels of important regulatory proteins and preventing proteasome clogging, to ensure recovery after the oxidative insult has subsided.

The members of the CCR family described in this study are greatly varied in their alternative functions beyond their moonlighting roles as $20 \mathrm{~S}$ proteasome inhibitors. Multiple roles for DJ-1 have been described, such as DNA repair (52) and methylglyoxalate activity (67). NQO1 and NQO2 are both members of the quinone reductase family $(20,71)$, while other CCRs are involved in various metabolic pathways, such as carbonyl reduction (CBR3) (57), prostaglandin inactivation (PGDH) (63), and serine hydrolysis (RBBP9) (59). In addition, multiple members of the Ras superfamily, which are small GTPases involved in cell proliferation, morphology, signaling, transport, and so on (29), are represented in the CCRs. In addition to those CCRs that were analyzed in this study, there are other candidates that still need to be explored (Table 1). These include more members of the Ras superfamily, electron transfer flavoprotein $\mathrm{B}$, the $\beta$ subunit of the electron transfer flavoprotein complex in the mitochon-

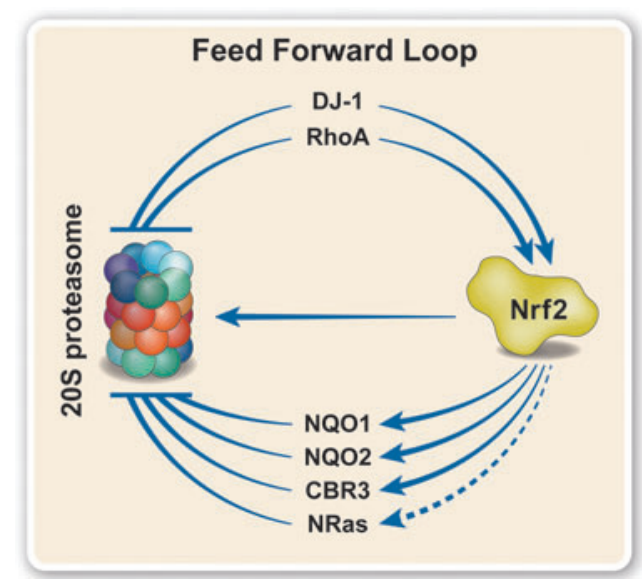

FIG. 7. CCRs organize into a feed-forward regulatory loop with Nrf2 and the $20 S$ proteasome. During oxidative stress, Nrf2 translocates to the nucleus to initiate the oxidative stress response by transcription of target genes, including subunits of the 20S proteasome and the CCRs NQO1, NQO2, and CBR3. NRas is basally transcribed by Nrf2 (indicated by dashed line). DJ-1, RhoA, and PGDH act upstream of Nrf2 to stabilize its levels. All the CCRs concurrently inhibit the $20 \mathrm{~S}$ proteasome, preventing the degradation of its substrates, dampening the effect of the increased $20 \mathrm{~S}$ proteasome levels during oxidative stress, protecting the cell from damaging imbalances and proteasome clogging, and ensuring a rapid recovery. dria, known to generate free radicals and therefore contribute to oxidative stress (53), and phosphoglycerate mutase 1, an enzyme in the glycolytic pathway (10). The varying roles of the CCRs, along with the ability to inhibit the $20 \mathrm{~S}$ proteasome, suggest that the dual functionality of these proteins may be important for focused inhibition of the 20 S proteasome in association with specific metabolic or signaling pathways, in a spatiotemporal manner. In support of this hypothesis, research has shown that RBBP9 is located in the extranuclear compartment (59), CBR3 and NQO2 are cytoplasmic $(43,71)$, RhoA is associated with the cytoskeleton, and NRas, KRas, and HRas shuttle between the cytoplasmic membrane and the cytosol depending on their nucleotide state (29). It has been shown that the free, constitutive $20 \mathrm{~S}$ proteasome also localizes to different cellular compartments $(6,9,23)$, and therefore, the presence of location-specific regulators may be vital to ensure that $20 \mathrm{~S}$ proteasomal degradation occurs at an appropriate pace and on the necessary substrates in each location in the cell.

Many of the CCRs are also associated with mutation- or expression-driven pathologies, such as neurodegenerative disease and various cancers. For example, missense mutations in DJ-1 are known to cause early-onset Parkinson's disease $(16,35)$, and intriguingly, one of these mutants was shown to be able to inhibit the $20 \mathrm{~S}$ proteasome more effectively than wild-type DJ-1 (5). Mutations in NQO1 have been correlated with an increased risk of Alzheimer's disease (7, 68), while changes in PGDH expression have been linked to tumor growth in multiple cancers $(64,73)$, as well as latestage neurodegenerative disease (44). Preliminary links have been found between changes in RBBP9 levels and ALS progression (39) as well as pancreatic cancer (59). RhoA overexpression is associated with cancer progression (75), and the Ras family of proteins is famously associated with numerous oncogenetic mutations, leading to constitutively activated Ras proteins that drive the development and growth of multiple cancers (33). Moreover, many cancers and neurodegenerative diseases are also associated with oxidative stress $(36,51)$, and as described here, most of the CCRs analyzed are involved in the oxidative stress response. It is therefore tempting to speculate that given the dual roles of these moonlighting proteins, mutations or changes in their expression may also affect their ability to inhibit the $20 \mathrm{~S}$ proteasome and participate in the oxidative stress response, thus leading to imbalances in the levels of $20 \mathrm{~S}$ proteasome substrates, compounding the negative effects on the cell.

The discovery of the CCR family was based on the presence of a Rossmann fold and the conserved N-terminal sequence motif found across NQO1 and DJ-1 homologues (Fig. 3). Considering that Rossmann folds are one of the most common structural motifs found in proteins (32), it is likely that many more proteins exist that share these features, but whose structures are yet to be elucidated. In addition, the Rossmann fold is one of the most ancient protein folds, found even in ancient organisms such as archaea (40). The conservation of function of the CCRs in regulating the $20 \mathrm{~S}$ proteasome from archaea (Fig. 2 and Supplementary Fig. S5) indicates that this regulatory interaction may have evolved early in evolution, possibly even before the evolution of the $26 \mathrm{~S}$ proteasome pathway, demonstrating the importance of modulating the degradation of proteins by the $20 \mathrm{~S}$ proteasome. Therefore, the CCR family may actually contain 
many more members than those described here, making the regulatory network of the $20 \mathrm{~S}$ proteasome far more wide reaching than currently thought. Future research into the CCRs analyzed in this study, and the potential discovery of more members of this family, will be critical for mapping the global network of proteasome regulators, as well as for elucidating the exact mechanistic details of $20 \mathrm{~S}$ proteasome regulation.

The clinical success of proteasome inhibitors, such as bortezomib for the treatment of multiple myeloma and mantle cell lymphoma, is testament to the potential of the proteasome pathways as drug targets (69). However, the inability of these proteasome inhibitors to distinguish between the $26 \mathrm{~S}$ and $20 \mathrm{~S}$ proteasomes, which as described here display different functions and are regulated by different mechanisms, has been a drawback of these therapies, leading to unwanted and deleterious side effects (27). As such, exploiting this novel $20 \mathrm{~S}$ proteasome-specific regulation, possibly via a conserved mechanism shared by the CCRs, could open avenues for the development of novel $20 \mathrm{~S}$ proteasome-specific inhibitors to treat diseases of proteasome dysfunction.

\section{Materials and Methods}

\section{Cell lines}

HEK293T cells stably expressing the $\beta 4$ subunit of the proteasome tagged with a C-terminal FLAG tag were obtained from Chaim Kahana (Weizmann Institute of Science). Wild-type HEK293T cells were obtained from Eitan Reuveny (Weizmann Institute of Science). The mouse fibroblast cell line A31N-ts20 BALB/c and human mammary epithelial MCF10A cells were obtained from Yosef Shaul (Weizmann Institute of Science).

HEK293T and A31N-ts20 BALB/c cells were maintained in Dulbecco's modified Eagle's medium (Sigma) supplemented with $10 \%$ fetal bovine serum (Gibco), $100 \mathrm{U} / \mathrm{mL}$ penicillin $/ 100 \mu \mathrm{g} / \mathrm{mL}$ streptomycin (Biological Industries), $0.1 \mathrm{~m} M$ sodium pyruvate (Biological Industries), modified Eagle's medium-Eagle nonessential amino acids (Biological Industries), and MycoZap Prophylactic (Lonza) according to the manufacturer's instructions. $\beta 4-F L A G$ HEK293T cells were additionally supplemented with $1 \mathrm{mg} / \mathrm{mL}$ puromycin. MCF10A cells were maintained in Dulbecco's modified Eagle's medium/nutrient mixture F-12 Ham (Sigma) (of note, this medium contains high levels of sodium pyruvate that neutralize externally added $\mathrm{H}_{2} \mathrm{O}_{2}$ ) supplemented with $5 \%$ donor horse serum (Gibco), $20 \mathrm{ng} / \mathrm{mL}$ epidermal growth factor (Sigma), $10 \mu \mathrm{g} / \mathrm{mL}$ insulin (Sigma), $0.5 \mu \mathrm{g} / \mathrm{mL}$ hydrocortisone (Sigma), $100 \mathrm{ng} / \mathrm{mL}$ cholera toxin (Sigma), $100 \mathrm{U} / \mathrm{mL}$ penicillin $/ 100 \mu \mathrm{g} / \mathrm{mL}$ streptomycin (Biological Industries), and $2 \mathrm{~m} M$ L-glutamine (Biological Industries). Cells were grown in a humidified incubator at $37^{\circ} \mathrm{C}$ (HEK293T, MCF10A) or $32^{\circ} \mathrm{C}(\mathrm{A} 31 \mathrm{~N}-\mathrm{ts} 20 \mathrm{BALB} / \mathrm{c})$ with a $5 \% \mathrm{CO}_{2}$ controlled atmosphere.

\section{Microbe strains}

The DH5 $\alpha$ strain of Escherichia coli was used for all plasmid cloning experiments. The BL21(DE3) strain of $E$. coli was used for all recombinant protein expression experiments.

\section{Organisms as source for materials used in experiments}

The Saccharomyces cerevisiae strain RJD1144, generated in the laboratory of Raymond Deshaies, Caltech (CA), which contains a chromosomally FLAG-tagged $\beta 4$ (PRE1) subunit was used for the purification of yeast $20 \mathrm{~S}$ proteasome.

The Rattus norvegicus strain RCS was used as a source of liver for the purification of the mammalian $20 \mathrm{~S}$ proteasome.

\section{Bioinformatic analyses}

Sequences of DJ-1 and NQO1 homologues from multiple species were acquired from UniProtKB. MSAs were performed using Clustal Omega, figures were generated using ESPript (espript.ibcp.fr) and WebLogo (weblogo.berkeley .edu/logo.cgi). All CATH-annotated Rossmann fold containing proteins were imported from the Protein Data Bank, and the presence of the N-terminal motif $(\mathrm{MX}(1,4)[\mathrm{KR}]$ $(1,2)$ [AVIL]4) discovered in the MSAs was identified using FuzzPro (EMBOSS). Estimated protein expression levels across various human tissues were taken from the HIPED.

\section{Plasmids and cloning}

The following plasmids were acquired from Addgene: pT7-7 $\alpha$-syn WT (\#36046), pNIC28-Bsa4 CBR3 (\#38800), pET28-MHL NRASA (\#25256, containing truncated NRas amino acids 1-172), pET28-MHL KRASB (\#25153, containing truncated KRas amino acids 1-169, and Q61H mutation), pGEX2T-HRas (\#55653), and pNIC28-Bsa4 RhoA (\#73231, containing truncated RhoA amino acids 1-184). pGEM-T NQO2 (HG14634-G) was acquired from Sino Biological. Modifications made to the plasmids are as follows: pGEX2T-HRas was used as a template to amplify truncated HRas (amino acids 1-172) using the primer pair: forward 5' AACCTGTACTTCCAGGGTACCATGACAGA ATACAAGCTTGTG and reverse 5' CTCGAGTGCGGC CGCAAGCTTTCAGTTCAGTTTCCGCAAT. The amplified product was inserted into the pET28 plasmid using Infusion, introducing an N-terminal 6xHis tag and TEV cleavage site. pET28-MHL KRASB was used as a template to reverse the Q61H mutation, using the primer pair: forward 5' CAGCAGGTCAGGAGGAGTACA and reverse 5' TGTC GAGAATATCCAAGAGAC. pGEM-T NQO2 was used as a template to amplify NQO2 using the primer pair: forward $5^{\prime}$ AACCTGTACTTCCAGGGTACCATGGCAGGTAAGAA AGTACTCA and reverse 5' CTCGAGTGCGGCCGCAA GCTTTCATTGCCCGAAGTGC. The amplified product was inserted into the pET28 plasmid using Infusion, introducing an N-terminal 6xHis tag and TEV cleavage site.

Total RNA was extracted from HEK293T cells using NucleoZOL (Macherey-Nagel) according to the manufacturer's instructions. cDNA was synthesized using ProtoScript II Reverse Transcriptase $(\mathrm{NEB})$ and $\mathrm{d}(\mathrm{T})_{20}$ oligonucleotide according to the manufacturer's instructions. RBBP9 and PGDH were amplified from the cDNA using the primer pairs: RBBP9: forward 5' AACCTGTACTTCCAGGGTACCAT GGCTTCTCCTAGCAAGGCA and reverse 5' CTCGAGT GCGGCCGCAAGCTTCTATGCTGGTACTTTCAGCAA; and PGDH: forward 5' AACCTGTACTTCCAGGGTAC CATGCACGTGAACGGCAAAGTG and reverse 5' CTCG 
AGTGCGGCCGCAAGCTTTCATTGGGTTTTTGCTTGA

AATGGA. The amplified products were cloned into pET28 to introduce a C-terminal 6xHis tag.

The $\mathrm{pCDF} 1$ expression plasmid, used for mammalian cell transfection, was loaded with the following inserts amplified with their respective primer pairs: NQO2: forward 5' GGGCGCGCCGGATCCATGGCAGGTAAGAAAGTACT CATTG and reverse 5' CGCGGCCGCGAATTCTCATT GCCCGAAGTGCCAG; NQO2-HA: forward as for NQO2 and reverse $5^{\prime}$ TCGCGGCCGCGAATTCTCACGCATAG TCAGGAACATCGTATGGGTAACCTCCTTGCCCGAA GTGCCAGTGGGC; CBR3: forward 5' GGGCGCGCCG GATCCATGTCGTCCTGCAGCCGC and reverse $5^{\prime}$ CG CGGCCGCGAATTCTCACCAGTTTTGCACAACTTTG; PGDH: forward 5' GGGCGCGCCGGATCCATGCACGT GAACGGCAAAGTG and reverse 5' CGCGGCCGCGA ATTCTCATTGGGTTTTTGCTTGAAATGG; PGDH-HA: forward as for PGDH and reverse 5' TCGCGGCCGCG AATTCTCACGCATAGTCAGGAACATCGTATGGGTA ACCTCCTTGGGTTTTTGCTTGAAATGGAGTTG; NRasHA: forward 5' GAGCCCGGGCGCGCCGGATCCGCCAC CATGACTGAGTACAAACTGGTG and reverse $5^{\prime}$ TCGC GGCCGCGAATTCTCACGCATAGTCAGGAACATCGT ATGGGTAACCTCCGTTGAGTTTTTTCATTCGGTAC TGG; and RhoA-HA: forward 5' CGGGCGCGCCGGATC CATGGCTGCCATCCGGAAG and reverse $5^{\prime}$ TCGCGGC CGCGAATTCTCACGCATAGTCAGGAACATCGTATG GGTAACCTCCCCCACGTCTAGCTTGCAGAGC. Empty pCDF1 and pCFD1-GFP were obtained from Yardena Samuels (Weizmann Institute of Science).

\section{Protein expression and purification}

Purification of substrates $\alpha$-syn and OxCaM. BL21(DE3) was transformed with pT7-7 $\alpha$-syn WT. Cells were grown in LB medium supplemented with $100 \mu \mathrm{g} / \mathrm{mL}$ ampicillin at $37^{\circ} \mathrm{C}$ until they reached $\mathrm{OD}_{600} 0.8$. Protein expression was induced by the addition of $1 \mathrm{~m} M$ isopropyl- $\beta$-Dthiogalactoside (IPTG) for $3 \mathrm{~h}$ at $37^{\circ} \mathrm{C}$, after which the cells were moved to $16^{\circ} \mathrm{C}$ overnight. Cells were harvested by centrifugation at $5000 \mathrm{~g}$ for $10 \mathrm{~min}$, and resuspended in $50 \mathrm{~m} M$ Tris- $\mathrm{HCl} \mathrm{pH} \mathrm{8,} 50 \mathrm{~m} M \mathrm{KCl}, 5 \mathrm{~m} M$ magnesium acetate, $10 \mathrm{~m} M$ EDTA pH 8. Cells were lysed in a French Press and centrifuged at $12,000 \mathrm{~g}$ for $20 \mathrm{~min}$ to remove cellular debris. The supernatant was boiled for $15 \mathrm{~min}$, followed by centrifugation at $12,000 \mathrm{~g}$ for $20 \mathrm{~min}$ to remove insoluble proteins. The supernatant was collected and passed over a $Q$ anion exchange column pre-equilibrated with $20 \mathrm{~m} M$ Tris $\mathrm{pH}$ 8. After loading, the column was sequentially washed with $13 \%, 55 \%, 70 \%$, and $100 \% 20 \mathrm{mM}$ Tris $\mathrm{pH} 8,1 M$ $\mathrm{NaCl}$ to elute the protein. Fractions containing $\alpha$-syn were pooled and concentrated using a 3-kDa Amicon Ultra column (Millipore). Concentrated $\alpha$-syn was loaded onto a gel filtration column (Superdex 200, 10/300 GL; GE Healthcare), pre-equilibrated with $50 \mathrm{~m} M$ Tris $\mathrm{pH} 8,150 \mathrm{~m} M \mathrm{NaCl}$. Fractions containing $\alpha$-syn were collected, concentrated, frozen in liquid nitrogen, and stored at $-80^{\circ} \mathrm{C}$.

Calmodulin was purchased from Sigma as a lyophilized powder (P1431) and oxidized to produce OxCaM as previously described (25) with the following modification: instead of $50 \mathrm{~m} M$ HOMOPIPES $\mathrm{pH} 5,50 \mathrm{~m} M$ HEPES $\mathrm{pH} 7.5$ was used.
Purification of human DJ1 and yeast DJ-1 (Hsp32). DJ-1 and Hsp32 were expressed and purified as previously described (47). BL21(DE3) was transformed with pET-15bhDJ-1 or pET28-Hsp32. Cells were grown in LB medium supplemented with $100 \mu \mathrm{g} / \mathrm{mL}$ ampicillin or $50 \mu \mathrm{g} / \mathrm{mL}$ kanamycin, respectively, at $37^{\circ} \mathrm{C}$ until they reached $\mathrm{OD}_{600} 0.45$. Protein expression was induced by the addition of $0.4 \mathrm{mM}$ IPTG for $2.5 \mathrm{~h}$. Cells were harvested by centrifugation at $5000 \mathrm{~g}$ for $10 \mathrm{~min}$, and resuspended in $50 \mathrm{~mL}$ of $50 \mathrm{~m} M$ Tris$\mathrm{HCl} \mathrm{pH} \mathrm{7.4,} 2 \mathrm{~m} M$ EDTA, $1 \mathrm{~m} M$ DTT, $1 \mathrm{~m} M$ PMSF, and a protease inhibitor cocktail (Complete; Roche). Cells were lysed in a French Press, centrifuged for $10 \mathrm{~min}$ at $5000 \mathrm{~g}$ and the lysate was passed through a Source-15Q anion exchange $55 \mathrm{~mL}$ column (GE Healthcare) pre-equilibrated with $50 \mathrm{mM}$ Tris- $\mathrm{HCl} \mathrm{pH} \mathrm{7.4,} 1 \mathrm{mM}$ DTT. After lysate loading, proteins were eluted with $200 \mathrm{~mL}$ of $50 \mathrm{mM}$ Tris- $\mathrm{HCl} \mathrm{pH} \mathrm{7.4,1} \mathrm{mM}$ DTT. Fifty milliliter fractions were collected and DJ-1/Hsp32containing fractions (eluted after $150-200 \mathrm{~mL}$ ) were concentrated using a 3-kDa Amicon Ultra column (Millipore). Concentrated DJ-1/Hsp32 was loaded onto a gel filtration column (Superdex 200, 10/300 GL; GE Healthcare), preequilibrated with $50 \mathrm{~m} M$ Tris- $\mathrm{HCl} \mathrm{pH} \mathrm{7.4,300} \mathrm{mM} \mathrm{NaCl}$, and $1 \mathrm{~m} M$ DTT. DJ-1/Hsp32-containing fractions were combined, concentrated, frozen in liquid nitrogen, and stored at $80^{\circ} \mathrm{C}$.

Purification of archaea DJ-1. The BL21 (DE3) was transformed with pET28-taDJ-1. Cells were grown at $37^{\circ} \mathrm{C}$ to an $\mathrm{OD}_{600}$ of 0.5 in $100 \mathrm{~mL}$ LB medium supplemented with $50 \mu \mathrm{g} / \mathrm{mL}$ kanamycin. Protein expression was induced by the addition of $0.5 \mathrm{mM}$ IPTG for $7 \mathrm{~h}$ at $37^{\circ} \mathrm{C}$, and then, the cells were moved to $16^{\circ} \mathrm{C}$ for overnight protein expression. Cells were harvested by centrifugation for $20 \mathrm{~min}$ at $5000 \mathrm{~g}$ and resuspended in $50 \mathrm{~m} M$ Tris- $\mathrm{HCl} \mathrm{pH} \mathrm{7.5,} 50 \mathrm{mM} \mathrm{NaCl}, 20 \mathrm{~m} M$ imidazole, $250 \mathrm{U}$ benzonase (Millipore), $1 \mathrm{mM}$ PMSF. Cells were lysed by sonication and the lysate was centrifuged for $30 \mathrm{~min}$ at $40,000 \mathrm{~g}$. The supernatant was loaded onto a HisTrap FF $5 \mathrm{~mL}$ column (GE Healthcare) pre-equilibrated with $50 \mathrm{~m} M$ Tris- $\mathrm{HCl}, 50 \mathrm{~m} M \mathrm{NaCl}$, and $20 \mathrm{~m} M$ imidazole. After lysate loading, protein was eluted with $0 \%-100 \%$ gradient elution buffer $(50 \mathrm{~m} M$ Tris- $\mathrm{HCl} \mathrm{pH} \mathrm{7.5,} 300 \mathrm{mM} \mathrm{NaCl}$, and $500 \mathrm{~m} M$ imidazole). taDJ-1 containing fractions were pooled and dialyzed with TEV protease against $50 \mathrm{~m} M$ Tris $\mathrm{pH}$ 7.4, $1 \mathrm{~m} M$ EDTA, and $2 \mathrm{~m} M$ DTT. Following the overnight TEV cleavage, the taDJ-1 was loaded on HisTrap FF $5 \mathrm{~mL}$, and flow through fraction was collected, concentrated, frozen in liquid nitrogen, and stored at $-80^{\circ} \mathrm{C}$.

Purification of NQO2. BL21(DE3) was transformed with the pET28-NQO1 or pET28-NQO2. Cells were grown in LB medium supplemented with $50 \mu \mathrm{g} / \mathrm{mL}$ kanamycin at $37^{\circ} \mathrm{C}$ until they reached $\mathrm{OD}_{600} 0.45$. Protein expression was induced by the addition of $0.4 \mathrm{~m} M$ IPTG for $2.5 \mathrm{~h}$. Cells were harvested by centrifugation and lysed by sonication in $50 \mathrm{mM}$ Tris- $\mathrm{HCl}$ ( $\mathrm{pH} 7.5), 150 \mathrm{mM} \mathrm{NaCl}$, and $1 \mathrm{mM}$ PMSF. Cellular debris was removed by sonication, and the supernatant was passed over a HisTrap FF column (GE Healthcare). HisTEV-NQO1 or His-TEV-NQO2 was eluted over a gradient up to $400 \mathrm{~m} M$ imidazole. Fractions containing the proteins were pooled and TEV protease was added. The sample was incubated at room temperature for $4 \mathrm{~h}$, followed by overnight dialysis against $50 \mathrm{~m} M$ Tris- $\mathrm{HCl}(\mathrm{pH} 7.5) 150 \mathrm{mM} \mathrm{NaCl}$. The dialyzed protein was passed over a HisTrap FF column to 
remove the TEV protease and any uncleaved protein. The flow-through was collected and concentrated using a $10 \mathrm{kDa}$ Amicon Ultra column (Millipore), and loaded onto a gel filtration column (Superdex 200, 10/300 GL; GE Healthcare) pre-equilibrated with $20 \mathrm{~m} M$ Tris- $\mathrm{HCl}$ (pH 7.4), $50 \mathrm{mM}$ $\mathrm{NaCl}$. NQO1 or NQO2 containing fractions were pooled, concentrated, frozen in liquid $\mathrm{N}_{2}$, and stored at $-80^{\circ} \mathrm{C}$.

Purification of CBR3. BL21(DE3) was transformed with pNIC28Bsa4-CBR3. Cells were grown in LB medium supplemented with $50 \mu \mathrm{g} / \mathrm{mL}$ kanamycin at $37^{\circ} \mathrm{C}$ until they reached $\mathrm{OD}_{600} 0.6$. Protein expression was induced by the addition of $1 \mathrm{~m} M$ IPTG for $3 \mathrm{~h}$. Cells were harvested by centrifugation at $5000 \mathrm{~g}$ for $10 \mathrm{~min}$, and resuspended in $20 \mathrm{~m} M$ sodium dihydrogen phosphate $\mathrm{pH} 7.4,20 \mathrm{~m} M$ imidazole, $150 \mathrm{~m} M \mathrm{NaCl}, 0.26 \mathrm{~m} M$ PMSF, $1 \mathrm{~m} M$ benzamidine, and $1.4 \mu \mathrm{g} / \mathrm{mL}$ pepstatin. Cells were disrupted by the addition of $1 \mathrm{mg} / \mathrm{mL}$ lysozyme followed by rolling at $4^{\circ} \mathrm{C}$ for $30 \mathrm{~min}$, and sonication ( $40 \% \mathrm{amp}, 30$-s pulses for $7.5 \mathrm{~min}$ ). The lysed cells were centrifuged at $18,000 \mathrm{rpm}$ for $45 \mathrm{~min}$ at $4^{\circ} \mathrm{C}$ to remove cellular debris. The supernatant was applied to a HisTrapHP column pre-equilibrated in $20 \mathrm{~m} M$ sodium dihydrogen phosphate $\mathrm{pH} 7.4,20 \mathrm{~m} M$ imidazole, and $150 \mathrm{~m} M$ $\mathrm{NaCl}$. His-TEV-CBR3 was eluted with a linear gradient to $400 \mathrm{~m} M$ imidazole over $40 \mathrm{~mL}$. Fractions containing HisTEV-CBR3 were pooled and incubated at room temperature for $3 \mathrm{~h}$ with TEV protease. The cleaved sample was dialyzed overnight against $20 \mathrm{~m} M$ sodium dihydrogen phosphate $\mathrm{pH}$ $7.4,150 \mathrm{mM} \mathrm{NaCl}$, and then reapplied to a HisTrapHP column to remove uncleaved protein and TEV protease. The flowthrough was collected, concentrated using a $10 \mathrm{kDa}$ Amicon Ultra column (Millipore), and loaded onto a gel filtration column (Superdex 200, 10/300 GL; GE Healthcare) preequilibrated with $20 \mathrm{mM}$ sodium dihydrogen phosphate $\mathrm{pH}$ 7.4, and $50 \mathrm{~m} M \mathrm{NaCl}$. CBR3 containing fractions were pooled, concentrated, frozen in liquid $\mathrm{N}_{2}$, and stored at $-80^{\circ} \mathrm{C}$.

Purification of PGDH and RBBP9. BL21(DE3) was transformed with pET28-PGDH or pET28-RBBP9 with a C-terminal 6xHis tag. Proteins were purified as for CBR3 with the following changes. After elution from the first HisTrapHP column, fractions containing PGDH-His or RBBP9His were concentrated and loaded onto a gel filtration column (Superdex 200, 10/300 GL; GE Healthcare) pre-equilibrated

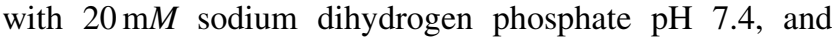
$50 \mathrm{~m} M \mathrm{NaCl}$. Fractions containing PGDH-His or RBBP9-His were pooled, concentrated, frozen in liquid $\mathrm{N}_{2}$, and stored at $-80^{\circ} \mathrm{C}$.

Purification of NRas, KRas, HRas, and RhoA. BL21(DE3) transformed with pET28-MHL NRASA, pET28-MHL KRASB (H61), pET28-HRas, or pNIC28-Bsa4 RhoA was induced and purified as for $\mathrm{CBR} 3$ with the following changes. Cells were resuspended in $20 \mathrm{~m} M$ Tris- $\mathrm{HCl} \mathrm{pH} 7.4,20 \mathrm{~m} M$ imidazole, $150 \mathrm{~m} M \mathrm{NaCl}, 0.26 \mathrm{~m} M$ PMSF, $1 \mathrm{~m} M$ benzamidine, and $1 \mu \mathrm{g} / \mathrm{mL}$ pepstatin. TEV cleaved proteins were

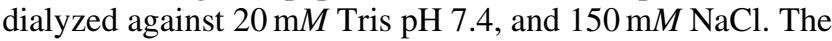
Superdex 200 10/300 GL gel filtration column was preequilibrated in $20 \mathrm{~m} M$ Tris $\mathrm{pH} 7.4$, and $50 \mathrm{mM} \mathrm{NaCl}$.

Purification of mammalian 20S proteasomes. Purification of the rat $20 \mathrm{~S}$ proteasome was performed as described previously (47). In brief, rat livers were homogenized in buffer containing $20 \mathrm{~m} M$ Tris- $\mathrm{HCl} \mathrm{pH} 7.5,1 \mathrm{~m} M$ EDTA, $1 \mathrm{~m} M$ DTT, and $250 \mathrm{~m} M$ sucrose. The extract was subjected to centrifugation at $1000 \mathrm{~g}$ for $15 \mathrm{~min}$. The supernatant was then diluted to $400 \mathrm{~mL}$ to a final concentration of $0.5 \mathrm{M} \mathrm{NaCl}$ and $1 \mathrm{~m} M$ DTT and subjected to ultracentrifugation for $2.2 \mathrm{~h}$ at $145,000 \mathrm{~g}$. The supernatant was centrifuged again at $150,000 \mathrm{~g}$ for $6 \mathrm{~h}$. The pellet containing the proteasomes was resuspended in $20 \mathrm{~m} M$ Tris- $\mathrm{HCl} \mathrm{pH} 7.5$ and loaded onto $1.8 \mathrm{~L}$ Sepharose 4B resin. Fractions containing the $20 \mathrm{~S}$ proteasome were identified by their ability to hydrolyze the fluorogenic peptide suc-LLVY-AMC, in the presence of $0.02 \%$ sodium dodecyl sulfate (SDS). Proteasome-containing fractions were then combined and loaded onto four successive anion exchange columns: Source Q15, HiTrap, DEAE FF, and Mono Q 5/50 GL (GE Healthcare). Elution was performed with a 0 - to $1-M \mathrm{NaCl}$ gradient. Active fractions were combined, and buffer exchanged to $10 \mathrm{~m} M$ phosphate buffer $\mathrm{pH} 7.4$ containing $10 \mathrm{mM} \mathrm{MgCl} 2$ using $10 \mathrm{kDa}$ Vivaspin $20 \mathrm{~mL}$ columns (GE Healthcare). Samples were then loaded onto a CHT ceramic hydroxyapatite column (Bio-Rad Laboratories, Inc.); a linear gradient of 10-400 $\mathrm{m} M$ phosphate buffer was used for elution. The purified $20 \mathrm{~S}$ proteasomes were analyzed by SDS-polyacrylamide gel electrophoresis (SDS-PAGE), activity assays, and MS analysis.

Purification of yeast $20 \mathrm{~S}$ proteasomes. S. cerevisiae expressing FLAG-tagged 20S proteasome (Pre1) was grown in $4 \times 700 \mathrm{~mL}$ YPD medium overnight at $30^{\circ} \mathrm{C}$. Cells were harvested at $5000 \mathrm{~g}$ for $20 \mathrm{~min}$, and the pellets rinsed in $10 \mathrm{~mL}$ water and centrifuged again at $5000 \mathrm{~g}$ for $20 \mathrm{~min}$. The pellet was resuspended in $100 \mathrm{~mL}$ lysis buffer containing $50 \mathrm{~m} M$ Tris- $\mathrm{HCl}$ pH 7.5, $150 \mathrm{~m} M \mathrm{NaCl}, 10 \%$ glycerol, $5 \mathrm{~m} M$ $\mathrm{MgCl}_{2}, 1 \mathrm{~m} M$ PMSF, protease inhibitor cocktail (Complete; Roche), and $250 \mathrm{U}$ benzonase (Millipore). Cells were lysed using a glass bead beater and prechilled with $50 \%$ glycerol and dry ice, with 1-min pulses for $7 \mathrm{~min}$ in total. The lysed cells were separated from the glass beads and centrifuged at $35,000 \mathrm{~g}$ for $20 \mathrm{~min}$ at $4^{\circ} \mathrm{C}$ to remove cell debris. The supernatant was collected, incubated with $2 \mathrm{~mL}$ anti-FLAG M2 affinity gel (Sigma), and prerinsed with sequential washes of lysis buffer, glycine $\mathrm{pH} 3.5$, and lysis buffer, for $1.5 \mathrm{~h}$ at $4{ }^{\circ} \mathrm{C}$ while gently rotating. The beads were collected, washed sequentially with lysis buffer containing $0.2 \%$ NP40, lysis buffer, and lysis buffer containing $500 \mathrm{mM} \mathrm{NaCl}$. The last wash was incubated on the beads for $1 \mathrm{~h}$ at $4^{\circ} \mathrm{C}$, followed by a final wash in lysis buffer. 20S proteasomes were eluted using $500 \mathrm{mg} / \mathrm{mL}$ FLAG peptide in lysis buffer containing $15 \%$ glycerol.

Purification of archaea 20S proteasomes. The $\alpha$ and $\beta$ subunits of Thermoplasma acidophilum $20 \mathrm{~S}$ proteasome were expressed as separate fusion proteins with a TEVcleavable His tag $(\alpha)$ or with NusA-His tag $(\beta)$ in BL21 (DE3) cells. Expression of both subunits was induced with the addition of $1 \mathrm{~m} M$ IPTG, $37^{\circ} \mathrm{C}$ for $3 \mathrm{~h}(\alpha)$ or for $5 \mathrm{~h}(\beta)$ at $37^{\circ} \mathrm{C}$. Cells were collected by centrifugation at $5000 \mathrm{~g}$ for $20 \mathrm{~min}$. Cells were lysed by sonication in $50 \mathrm{~m} M$ sodium phosphate buffer $\mathrm{pH} 8.0$, supplemented with protease inhibitors $(0.5 \mathrm{~m} M$ benzamidine, $0.1 \mathrm{mg} / \mathrm{mL}$ pepstatin $\mathrm{A}$, and $0.1 \mu M$ PMSF), $0.88 \mathrm{mg} / \mathrm{mL}$ lysozyme, and $250 \mathrm{U}$ benzonase (Millipore). After centrifugation at $40,000 \mathrm{~g}$ for $30 \mathrm{~min}$, the 
supernatant was loaded onto a HisTrap FF (GE Healthcare) pre-equilibrated in $50 \mathrm{~m} M$ sodium phosphate buffer $\mathrm{pH} 8.0$, $200 \mathrm{~m} M \mathrm{NaCl}$, and $10 \mathrm{~m} M$ imidazole. The $\alpha$ and $\beta$ subunits were eluted in $100 \mathrm{~m} M$ sodium phosphate buffer $\mathrm{pH} 7.8$, and $300 \mathrm{~m} M$ imidazole. The fractions containing the fusion protein were pooled and dialyzed overnight with TEV protease against $50 \mathrm{~m} M$ Tris $\mathrm{pH} \mathrm{7.4,} 1 \mathrm{~m} M$ EDTA, and $2 \mathrm{~m} M$ DTT. Following the overnight TEV cleavage, the $\alpha$ and $\beta$ subunits were loaded onto a HisTrap FF column and flow-through fractions were collected. The full proteasome $\left(\alpha_{7} \beta_{7} \beta_{7} \alpha_{7}\right)$ was assembled by mixing a slight molar excess of $\alpha$ subunit over $\beta$ subunit, and incubated at $37^{\circ} \mathrm{C}$ for $6 \mathrm{~h}$. The mixture was then concentrated to $0.5 \mathrm{~mL}$ and incubated overnight at $37^{\circ} \mathrm{C}$. The assembled $20 \mathrm{~S}$ proteasome complex was loaded onto a Superdex 200 10/300 GL (GE Healthcare) preequilibrated in $50 \mathrm{~m} M$ sodium phosphate buffer $\mathrm{pH} 7.5$, and $200 \mathrm{~m} M \mathrm{NaCl}$.

\section{Proteasome degradation assays}

To monitor the ability of proteins to regulate the activity of the $20 \mathrm{~S}$ proteasome in vitro, $10 \mu M$ of the CCRs or MG132 was preincubated with $0.1 \mu M$ of the $20 \mathrm{~S}$ proteasome for $30 \mathrm{~min}$ on ice in $50 \mathrm{~m} M$ HEPES pH 7.5. To initiate the assay, $\alpha$-syn was added to $1 \mu M$, and the reaction mixtures were incubated at $37^{\circ} \mathrm{C}$. For experiments using yeast or archaea $20 \mathrm{~S}$ proteasomes, the experiments were performed at $25^{\circ} \mathrm{C}$. Ten-microliter samples were taken every $30 \mathrm{~min}$ for $120 \mathrm{~min}$, quenched by the addition of reducing sample buffer and snap frozen in liquid $\mathrm{N}_{2}$. After all time points were collected, the samples were thawed, boiled for $5 \mathrm{~min}$, and loaded onto a $15 \%$ SDS-PAGE gel. Gels were stained with Coomassie brilliant blue, and changes in the level of $\alpha$-syn were quantified by band densitometry using ImageJ, normalized to T0, and plotted using GraphPad Prism.

Degradation assays using OxCaM were performed in the same way with minor modifications. OxCaM was added to a final concentration of $2.5 \mu M$, and time points were collected every hour for $4 \mathrm{~h}$. Assays performed with RBBP9, NRas, KRas, HRas, and RhoA were analyzed by Western blot with the anti-calmodulin antibody, due to these CCRs being the same size as OxCaM.

\section{Proteasome activity assays}

Proteasome activity assays were performed as previously described (47). In brief, between 0.1 and $0.3 \mu M, 20 \mathrm{~S}$ proteasomes were incubated either alone or with $10 \mu M \mathrm{MG} 132$ or CCRs in $25 \mathrm{~m} M$ HEPES pH 7.5 for $30 \mathrm{~min}$ on ice. Four microliters of the mixture was combined with $40 \mu \mathrm{L} 25 \mathrm{mM}$ HEPES pH 7.5 containing $100 \mu M$ Suc-LLVY-AMC and $0.02 \%$ SDS. Samples were incubated at $30^{\circ} \mathrm{C}$ for $30 \mathrm{~min}$ in the dark. To stop the reaction, $200 \mu \mathrm{L}$ of $1 \%$ SDS was added to the mixture. The fluorescence of hydrolyzed AMC groups was measured with a microplate reader (Infinite 200; Tecan Group), using an excitation filter of $380 \mathrm{~nm}$ and an emission filter of $460 \mathrm{~nm}$.

\section{Native mass spectrometry analysis}

Nanoflow electrospray ionization MS and tandem MS experiments were conducted under nondenaturing conditions on a Q-Exactive Plus Orbitrap EMR (Thermo Fisher Scien- tific). Before MS analysis, $20 \mu \mathrm{L}$ of up to $100 \mathrm{~m} M$ sample was buffer exchanged into 0.5-1 $M$ ammonium acetate $\mathrm{pH} 7.5$, using Bio-Spin columns (Bio-Rad). Assays were performed in positive ion mode and conditions were optimized to enable the ionization and removal of adducts, without disrupting the noncovalent interactions of the proteins tested. In MS/MS experiments, the relevant $\mathrm{m} / \mathrm{z}$ values were isolated and argon gas was admitted to the collision cell. Spectra are shown without smoothing or background subtraction. Typically, aliquots of $2 \mu \mathrm{L}$ of sample were electrosprayed from goldcoated borosilicate capillaries prepared in-house. The following experimental conditions were used on the Q-Exactive Plus Orbitrap EMR: capillary voltage $1.7 \mathrm{kV}$, MS spectra were recorded at low resolution (5000), and the high-energy collision dissociation (HCD) cell voltage was set to $20-50 \mathrm{~V}$, at trapping gas pressure setting of 3.9. For MS/MS analyses, a wide isolation window of $\pm 2000 \mathrm{~m} / \mathrm{z}$ around the most intense charge state of the $20 \mathrm{~S}$ proteasome (around 12,000 $\mathrm{m} / \mathrm{z}$ ) was set in the quadrupole, allowing the transmission of only high $\mathrm{m} / \mathrm{z}$ species. Transmitted ions were subjected to collisioninduced dissociation in the HCD cell, at an accelerating voltage of $200 \mathrm{~V}$, and the trapping gas pressure was set to 1.5 .

\section{Immunoprecipitation}

HEK293T cells stably expressing the FLAG- $\beta_{4}$ proteasome subunit were plated in four $15-\mathrm{cm}$ dishes, at a density of $1.5 \times 10^{6}$ cells per dish. Each plate was transfected with $20 \mu \mathrm{g}$ of pCDF1-NQO2-HA, pCDF1-PGDH-HA, pCDF1-NRas$\mathrm{HA}$, or pCDF1-RhoA-HA and grown for $48 \mathrm{~h}$. Cells were collected by trypsinization, combined, washed in phosphatebuffered saline, and resuspended in $1 \mathrm{~mL}$ lysis buffer $(20 \mathrm{mM}$ HEPES pH 7.4, $10 \%$ glycerol, $10 \mathrm{~m} M \mathrm{NaCl}, 3 \mathrm{mM} \mathrm{MgCl}_{2}$, and $1 \mathrm{~m} M$ ATP) and protease inhibitors (1 $\mathrm{m} M$ PMSF, $1 \mathrm{~m} M$ benzamidine, and $1.4 \mu \mathrm{g} / \mathrm{mL}$ pepstatin). Cells were incubated on ice for $15 \mathrm{~min}$ and homogenized in a glass-Teflon homogenizer for 40 strokes. Lysate was cleared by centrifugation at $18,000 \mathrm{~g}$ for $10 \mathrm{~min}$ at $4^{\circ} \mathrm{C}$. For IP using anti-FLAG affinity gel, $1 \mathrm{mg}$ protein was diluted in $500 \mu \mathrm{L}$ lysis buffer. $\mathrm{NaCl}$ concentration was adjusted to $150 \mathrm{~m} M$ and rotated overnight at $4^{\circ} \mathrm{C}$ in the presence of $45 \mu \mathrm{L}$ anti-FLAG M2 affinity gel (Sigma). The following morning, beads were washed three times with lysis buffer containing $150 \mathrm{mM}$ $\mathrm{NaCl}$ and boiled in $55 \mu \mathrm{L}$ reducing sample buffer. For IP using anti-HA or anti-Rpn2 antibodies, $1 \mathrm{mg}$ protein was diluted in $500 \mu \mathrm{L}$ lysis buffer. $\mathrm{NaCl}$ concentration was adjusted to $150 \mathrm{~m} M$. Proteins were precleared using $40 \mu \mathrm{L}$ of Protein G Sepharose (GE Healthcare), for $1 \mathrm{~h}$ at $4{ }^{\circ} \mathrm{C}$, at a gentle rotation. The beads were discarded and the lysate was rotated overnight at $4{ }^{\circ} \mathrm{C}$ in the presence of $9 \mu \mathrm{L}$ anti-HA rabbit (ab9110; Abcam) or $9 \mu \mathrm{L}$ anti-Rpn2 (PSMD1, ab140682; Abcam) antibody. The following morning, $45 \mu \mathrm{L}$ Protein G Sepharose beads (GE Healthcare) were added, and lysate was rotated for $2 \mathrm{~h}$ at $4^{\circ} \mathrm{C}$. The beads were then washed three times in lysis buffer containing $150 \mathrm{mM} \mathrm{NaCl}$ and boiled in $55 \mu \mathrm{L}$ protein sample buffer.

\section{CCR overexpression}

A31N-ts20 BALB/c cells were transfected by electroporation using an NEPA21 electroporator (Nepa Gene Co., Ichikawa-City, Japan). For electroporation, $2 \times 10^{6}$ cells were mixed with $20 \mu \mathrm{g}$ pCDF1 plasmid containing GFP, NQO2, 
CBR3, or PGDH, and transfected according to the manufacturer's instructions, using a poring pulse of $125 \mathrm{~V}$ for $5 \mathrm{~ms}$. After electroporation, cells were cultured at $32^{\circ} \mathrm{C}$ for $24 \mathrm{~h}$. The growth medium was then replaced and the cells returned to $32^{\circ} \mathrm{C}$ for $24 \mathrm{~h}$. Cells were transferred to $39^{\circ} \mathrm{C}$ for $24 \mathrm{~h}$, or left at $32^{\circ} \mathrm{C}$ as indicated. Seventy-two hours post-transfection, the cells were collected and lysed in modified RIPA buffer containing $50 \mathrm{~m} M$ HEPES $\mathrm{pH} 7.5$, $150 \mathrm{~m} M \mathrm{NaCl}, 1 \% \mathrm{NP}-40,0.25 \% \mathrm{Na}$-deoxycholate, $0.26 \mathrm{~m} M$ PMSF, $1 \mathrm{~m} M$ benzamidine, $1.4 \mu \mathrm{g} / \mathrm{mL}$ pepstatin, $4 \mathrm{~m} M \mathrm{Na}-$ pyrophosphate, $4 \mathrm{~m} M \beta$-glycerophosphate, and $5 \mathrm{~m} M \mathrm{Na}-$ orthovanadate. Cellular debris was removed by centrifugation, and the supernatant was collected. Total protein concentration was estimated by Bradford assay. For Western blot analysis, $30 \mu \mathrm{g}$ of total protein was loaded for each sample.

\section{Silencing and oxidative stress experiments}

The following siRNAs from Dharmacon (ON-TARGETplus SMARTpool) were used for silencing experiments: Nontargeting pool, Human NFE2L2 (Nrf2), Mouse NFE2L2, Human Park7 (DJ-1), Mouse Park7, Human RhoA, Mouse RhoA. MCF10A cells were transfected with human or mouse siRNAs, respectively, using jetPRIME transfection reagent (Polyplus) according to the manufacturer's instructions. After $24 \mathrm{~h}$, the cells were divided into three plates, allowing for replacement of the cell media, prevention of growth beyond confluency, and preparation of plates for oxidative stress time points. Oxidative stress was induced by adding DEM (since $\mathrm{H}_{2} \mathrm{O}_{2}$ is neutralized by their specialized growth media) to a final concentration of $150 \mu \mathrm{M}$ at 48 and $56 \mathrm{~h}$ post-transfection, allowing for DEM exposure of 24 and $16 \mathrm{~h}$, respectively, before collecting the cells at $72 \mathrm{~h}$ post-transfection.

\section{Cell fractionation}

MCF10A cells from a 6-cm tissue culture dish were resuspended in $70 \mu \mathrm{L}$ hypotonic buffer, containing $10 \mathrm{mM}$ HEPES pH 7.4, $10 \mathrm{~m} M \mathrm{KCl}, 1.5 \mathrm{mM} \mathrm{MgCl} 2,0.5 \% \mathrm{NP}-40$, $4 \mathrm{~m} M$ Na-pyrophosphate, $4 \mathrm{~m} M \beta$-glycerophosphate, $5 \mathrm{~m} M$ Na-orthovanadate, $0.26 \mathrm{~m} M$ PMSF, $1 \mathrm{~m} M$ benzamidine, and $1.4 \mu \mathrm{g} / \mathrm{mL}$ pepstatin, and incubated on ice for $10 \mathrm{~min}$. Five microliters of $10 \%$ NP-40 was added and cells were vortexed for $10 \mathrm{~s}$. The cytosolic fraction was separated from the nuclei by centrifugation at $2500 \mathrm{rpm}$ for $4 \mathrm{~min}$ and further clarified by centrifugation at $10,000 \mathrm{~g}$ for $10 \mathrm{~min}$. The nuclear pellet was washed in $0.1 \mathrm{~mL}$ hypotonic buffer and nuclei were pelleted at $2500 \mathrm{rpm}$ for $4 \mathrm{~min}$. Nuclei were then resuspended in $35 \mu \mathrm{L}$ hypertonic buffer, containing $20 \mathrm{~m} M$ HEPES $\mathrm{pH}$ 7.6, $100 \mathrm{~m} M \mathrm{NaCl}, 300 \mathrm{~m} M$ sucrose, $3 \mathrm{~m} M \mathrm{MgCl}_{2}, 1 \mathrm{~m} M$ $\mathrm{CaCl}_{2}, 0.5 \%$ TritonX-100, $0.26 \mathrm{~m} M$ PMSF, $1 \mathrm{~m} M$ benzamidine, and $1.4 \mu \mathrm{g} / \mathrm{mL}$ pepstatin, and incubated on ice for $3 \mathrm{~min}$. The nucleoplasmic fraction was separated by centrifugation at $5000 \mathrm{~g}$ for $5 \mathrm{~min}$. The pellet was resuspended in $28 \mu \mathrm{L}$ hypertonic buffer and incubated at room temperature for 15 min with 1000 gel units of micrococcal nuclease (NEB). Chromatin-bound proteins were released from the DNA by addition of $7 \mu \mathrm{L}$ of $1 M$ ammonium sulfate on ice for $5 \mathrm{~min}$, followed by centrifugation at $5000 \mathrm{~g}$ for $5 \mathrm{~min}$. Nucleoplasmic and chromatin-bound fractions were combined. Thirty micrograms of cytoplasmic and $20 \mu \mathrm{g}$ total nuclear fractions were loaded onto $12 \%$ SDS-PAGE gels, followed by Western blot analysis.

\section{Western blot}

After separation of samples on SDS-PAGE, proteins were transferred to $0.45 \mu \mathrm{m}$ immobilon-P PVDF membranes (Millipore) preactivated in methanol, in standard TrisGlycine transfer buffer ( $\mathrm{pH}$ 8.3) supplemented with $20 \%$ methanol for $2.5 \mathrm{~h}$ at $400 \mathrm{~mA}$. Membranes were blocked in $5 \%$ skim milk powder in TBS-T for $1 \mathrm{~h}$, followed by incubation with appropriate primary antibodies on an orbital shaker at $4^{\circ} \mathrm{C}$ overnight. Membranes were rinsed thoroughly in TBS-T, followed by incubation with appropriate secondary horseradish peroxidase (HRP)-conjugated antibodies for $1 \mathrm{~h}$ on an orbital shaker at room temperature. Membranes were rinsed thoroughly and developed using WesternBright ECL (Advansta) in myECL Imager (Thermo Scientific) according to the manufacturer's instructions.

Primary antibodies used for Western blots include anticalmodulin (1:1000, ab105498; Abcam), anti-HA rabbit (1:6000, ab9110; Abcam), anti-HA mouse (1:1000, ab18181; Abcam), anti-PSMD1 (1:1000, ab2941; Abcam), antiPSMA1 (1:1000, ab140499; Abcam), anti-FLAG (1:2500, F3165; Sigma), anti-GFP (1:2500, ab290; Abcam), antiNQO2 (1:500, sc271665; Santa Cruz), anti-CBR3 (1:1000, 15619-1-AP; Proteintech), anti-PGDH (1:200, sc271418; Santa Cruz), anti-p53 HRP (1:2500, HAF1355; Biotest), anti$\alpha$-syn (1:500, ab51252; Abcam), anti-GAPDH (1:1000, MAB374; Millipore), anti-ubiquitin (1:1000, PW0930; Enzo), anti-p21 (1:1000, ab109199; Abcam), anti- $\alpha$-tubulin (1:10,000, ab184613; Abcam), anti-Nrf2 (1:500, ab137500; Abcam), anti-histone H3 (1:1000, ab24834; Abcam), antiNQO1 (1:1000, ab28947; Abcam), anti-NRas (1:200, sc31; Santa Cruz), anti-DJ-1 (1:10,000, ab76008; Abcam), antiRhoA (1:200, sc418; Santa Cruz), and anti-RBBP9 (1:1000, 12230-2-AP; Proteintech).

Secondary antibodies used for Western blots include goat anti-mouse IgG-HRP (1:10,000, 115-035-003; Jackson) and goat anti-rabbit IgG-HRP (1:10,000, 111-035-003; Jackson).

\section{Quantification and statistical analysis}

Where indicated in the figure legends, at least three independent biological replicates were performed. The $n$ number of experiments and the details of the statistical analysis are described in the figure legends. Student's $t$-tests were performed to measure statistical significance, which is defined as $* p<0.05, * * p<0.01, * * * p<0.001$, and $* * * * p<0.0001$. All error bars correspond to standard error of the mean as indicated in the figure legends. Statistical analysis was performed using GraphPad Prism.

\section{Acknowledgments}

We thank Sarel Fleishmann and Gideon Schreiber for helpful discussions. We thank Yardena Samuels for generously providing NRas antibodies and the pCDF1 plasmid, and for helpful discussions. We thank Yossi Shaul for generously providing MCF10A cells. We thank Ron Rotkopf and Maria Fuzesi-Levi for helpful insights and discussions.

\section{Author Disclosure Statement}

No competing financial interests exist. 


\section{Funding Information}

We are also grateful for the support of a starting grant from the European Research Council (ERC) (Horizon 2020)/ERC grant agreement number 636752, and an Israel Science Foundation (ISF) grant 300/17. Maya A. Olshina is supported by a Deans Fellowship from the Faculty of Life Sciences, a Senior Postdoctoral Fellowship from the Koshland Fund, Weizmann Institute of Science, and a Postdoctoral Fellowship from the Israel Cancer Research Fund. Michal Sharon is an incumbent of the Aharon and Ephraim Katzir Memorial Professorial Chair.

\section{Supplementary Material}

Supplementary Table S1

Supplementary Figure S1

Supplementary Figure S2

Supplementary Figure S3

Supplementary Figure S4

Supplementary Figure S5

Supplementary Figure S6

Supplementary Figure S7

Supplementary Figure S8

Supplementary Figure S9

Supplementary Figure S10

\section{References}

1. Aiken CT, Wang X, Huang L, and Kaake RM. Oxidative stress-mediated regulation of proteasome complexes. $\mathrm{Mol}$ Cell Proteomics 10: R110.006924, 2011.

2. Asher G, Tsvetkov P, Kahana C, and Shaul Y. A mechanism of ubiquitin-independent proteasomal degradation of the tumor suppressors p53 and p73. Genes Dev 19: 316321, 2005.

3. Baugh JM and Pilipenko EV. 20S proteasome differentially alters translation of different mRNAs via the cleavage of eIF4F and eIF3. Mol Cell 16: 575-586, 2004.

4. Baugh JM, Viktorova EG, and Pilipenko EV. Proteasomes can degrade a significant proportion of cellular proteins independent of ubiquitination. J Mol Biol 386: 814-827, 2009.

5. Ben-Nissan G, Chotiner A, Tarnavsky M, and Sharon M. Structural characterization of missense mutations using high resolution mass spectrometry: a case study of the Parkinson's-related protein, DJ-1. J Am Soc Mass Spectrom 27: 1062-1070, 2016.

6. Ben-Nissan G and Sharon M. Regulating the 20S proteasome ubiquitin-independent degradation pathway. Biomolecules 4: 862-884, 2014.

7. Bian J-T, Zhao H-L, Zhang Z-X, Bi X-H, and Zhang J-W. Association of NAD(P)H:quinone oxidoreductase 1 polymorphism and Alzheimer's disease in Chinese. $\mathrm{J} \mathrm{Mol}$ Neurosci 34: 235-240, 2008.

8. Bornstein G, Bloom J, Sitry-Shevah D, Nakayama K, Pagano M, and Hershko A. Role of the SCFSkp2 ubiquitin ligase in the degradation of p21Cip1 in S phase. J Biol Chem 278: 25752-25757, 2003.

9. Breusing $\mathrm{N}$ and Grune T. Regulation of proteasomemediated protein degradation during oxidative stress and aging. Biol Chem 389: 203-209, 2008.

10. Chaneton B and Gottlieb E. PGAMgnam style: a glycolytic switch controls biosynthesis. Cancer Cell 22: 565-566, 2012.
11. Chen X, Barton LF, Chi Y, Clurman BE, and Roberts JM. Ubiquitin-independent degradation of cell-cycle inhibitors by the REG $\gamma$ proteasome. Mol Cell 26: 843-852, 2007.

12. Chen X, Chi Y, Bloecher A, Aebersold R, Clurman BE, and Roberts JM. N-acetylation and ubiquitin-independent proteasomal degradation of p21(Cip1). Mol Cell 16: 839-847, 2004.

13. Cheng Q, Kalabus JL, Zhang J, and Blanco JG. A conserved antioxidant response element (ARE) in the promoter of human carbonyl reductase 3 (CBR3) mediates induction by the master redox switch Nrf2. Biochem Pharmacol 83: 139-148, 2012.

14. Ciechanover A and Schwartz AL. Targeting proteins for destruction by the ubiquitin system: implications for human pathobiology. Annu Rev Pharmacol Toxicol 49: 73-96, 2009.

15. Clements CM, McNally RS, Conti BJ, Mak TW, and Ting JPY. DJ-1, a cancer- and Parkinson's diseaseassociated protein, stabilizes the antioxidant transcriptional master regulator Nrf2. Proc Natl Acad Sci US A 103: 15091-15096, 2006.

16. Cookson MR. Parkinsonism due to mutations in PINK1, Parkin, and DJ-1 and oxidative stress and mitochondrial pathways. Cold Spring Harb Perspect Med 2: a009415, 2012.

17. Davies KJA. Degradation of oxidized proteins by the $20 \mathrm{~S}$ proteasome. Biochimie 83: 301, 2001.

18. Demasi M and da Cunha FM. The physiological role of the free $20 \mathrm{~S}$ proteasome in protein degradation: a critical review. Biochim Biophys Acta Gen Subj 1862: 2948-2954, 2018.

19. DeNicola GM, Karreth FA, Humpton TJ, Gopinathan A, Wei C, Frese K, Mangal D, Yu KH, Yeo CJ, Calhoun ES, Scrimieri F, Winter JM, Hruban RH, Iacobuzio-Donahue C, Kern SE, Blair IA, and Tuveson DA. Oncogene-induced Nrf2 transcription promotes ROS detoxification and tumorigenesis. Nature 475: 106-109, 2011.

20. Dinkova-Kostova AT and Talalay P. NAD(P)H:quinone acceptor oxidoreductase 1 (NQO1), a multifunctional antioxidant enzyme and exceptionally versatile cytoprotector. Arch Biochem Biophys 501: 116-123, 2010.

21. Dyson HJ and Wright PE. Intrinsically unstructured proteins and their functions. Nat Rev Mol Cell Biol 6: 197-208, 2005.

22. Erales $\mathrm{J}$ and Coffino P. Ubiquitin-independent proteasomal degradation. Biochim Biophys Acta 1843: 216-221, 2014.

23. Fabre B, Lambour T, Delobel J, Amalric F, Monsarrat B, Burlet-Schiltz O, and Bousquet-Dubouch MP. Subcellular distribution and dynamics of active proteasome complexes unraveled by a workflow combining in vivo complex crosslinking and quantitative proteomics. Mol Cell Proteomics 12: 687-699, 2013.

24. Fabre B, Lambour T, Garrigues L, Ducoux-Petit M, Amalric F, Monsarrat B, Burlet-Schiltz O, and BousquetDubouch MP. Label-free quantitative proteomics reveals the dynamics of proteasome complexes composition and stoichiometry in a wide range of human cell lines. J Proteome Res 13: 3027-3037, 2014.

25. Ferrington DA, Sun H, Murray KK, Costa J, Williams TD, Bigelow DJ, and Squier TC. Selective degradation of oxidized calmodulin by the $20 \mathrm{~S}$ proteasome. J Biol Chem 276 : 937-943, 2001.

26. Finley D. Recognition and processing of ubiquitin-protein conjugates by the proteasome. Annu Rev Biochem 78: 477513, 2009. 
27. Frankland-Searby S and Bhaumik SR. The $26 \mathrm{~S}$ proteasome complex: an attractive target for cancer therapy. Biochim Biophys Acta 1825: 64-76, 2012.

28. Funes JM, Henderson S, Kaufman R, Flanagan JM, Robson M, Pedley B, Moncada S, and Boshoff C. Oncogenic transformation of mesenchymal stem cells decreases Nrf2 expression favoring in vivo tumor growth and poorer survival. Mol Cancer 13: 20, 2014.

29. Goitre L, Trapani E, Trabalzini L, and Retta SF. The Ras superfamily of small GTPases: the unlocked secrets. Methods Mol Biol 1120: 1-18, 2014.

30. Goldberg AL. Protein degradation and protection against misfolded or damaged proteins. Nature 426: 895-899, 2003.

31. Grune T, Catalgol B, Licht A, Ermak G, Pickering AM, Ngo JK, and Davies KJA. HSP70 mediates dissociation and reassociation of the $26 \mathrm{~S}$ proteasome during adaptation to oxidative stress. Free Radic Biol Med 51: 1355-1364, 2011.

32. Hanugoklu I. Proteopedia: Rossmann Fold: A beta-alphabeta fold at dinucleotide binding sites. Biochem Mol Biol Educ 43: 206-209, 2015.

33. Hobbs GA, Der CJ, and Rossman KL. RAS isoforms and mutations in cancer at a glance. J Cell Sci 129: 1287-1292, 2016.

34. Iakoucheva LM, Brown CJ, Lawson JD, Obradović Z, and Dunker AK. Intrinsic disorder in cell-signaling and cancerassociated proteins. J Mol Biol 323: 573-584, 2002.

35. Kahle PJ, Waak J, and Gasser T. DJ-1 and prevention of oxidative stress in Parkinson's disease and other age-related disorders. Free Radic Biol Med 47: 1354-1361, 2009.

36. Kim GH, Kim JE, Rhie SJ, and Yoon S. The role of oxidative stress in neurodegenerative diseases. Exp Neurobiol 24: 325-340, 2015.

37. Labbadia J and Morimoto RI. The biology of proteostasis in aging and disease. Annu Rev Biochem 84: 435-464, 2015.

38. Li X, Amazit L, Long W, Lonard DM, Monaco JJ, and O'Malley BW. Ubiquitin- and ATP-independent proteolytic turnover of p21 by the REGgamma-proteasome pathway. Mol Cell 26: 831-842, 2007.

39. Lilo E, Wald-Altman S, Solmesky LJ, Ben Yaakov K, Gershoni-Emek N, Bulvik S, Kassis I, Karussis D, Perlson E, and Weil M. Characterization of human sporadic ALS biomarkers in the familial ALS transgenic mSOD1(G93A) mouse model. Hum Mol Genet 22: 4720-4725, 2013.

40. Ma BG, Chen L, Ji HF, Chen ZH, Yang FR, Wang L, Qu G, Jiang YY, Ji C, and Zhang HY. Characters of very ancient proteins. Biochem Biophys Res Commun 366: 607-611, 2008.

41. Malhotra D, Portales-Casamar E, Singh A, Srivastava S, Arenillas D, Happel C, Shyr C, Wakabayashi N, Kensler TW, Wasserman WW, and Biswal S. Global mapping of binding sites for Nrf2 identifies novel targets in cell survival response through ChIP-Seq profiling and network analysis. Nucleic Acids Res 38: 5718-5734, 2010.

42. Mangan S and Alon U. Structure and function of the feedforward loop network motif. Proc Natl Acad Sci U S A 100: 11980-11985, 2003.

43. Miura T, Nishinaka T, and Terada T. Different functions between human monomeric carbonyl reductase 3 and carbonyl reductase 1. Mol Cell Biochem 315: 113, 2008.

44. Miyagishi H, Kosuge Y, Takano A, Endo M, Nango H, Yamagata-Murayama S, Hirose D, Kano R, Tanaka Y, Ishige $\mathrm{K}$, and Ito $\mathrm{Y}$. Increased expression of 15-hydroxy- prostaglandin dehydrogenase in spinal astrocytes during disease progression in a model of amyotrophic lateral sclerosis. Cell Mol Neurobiol 37: 445-452, 2017.

45. Moorthy AK, Savinova OV, Ho JQ, Wang VYF, Vu D, and Ghosh $\mathrm{G}$. The $20 \mathrm{~S}$ proteasome processes NF- $\kappa \mathrm{B} 1 \mathrm{p} 105$ into p50 in a translation-independent manner. EMBO $J$ 25: 1945-1956, 2006.

46. Morozov AV, Astakhova TM, Garbuz DG, Krasnov GS, Bobkova NV, Zatsepina OG, Karpov VL, and Evgen'ev MB. Interplay between recombinant $\mathrm{Hsp} 70$ and proteasomes: proteasome activity modulation and ubiquitinindependent cleavage of Hsp70. Cell Stress Chaperones 22: 687-697, 2017.

47. Moscovitz O, Ben-Nissan G, Fainer I, Pollack D, Mizrachi $\mathrm{L}$, and Sharon M. The Parkinson's-associated protein DJ-1 regulates the 20S proteasome. Nat Commun 6: 6609, 2015.

48. Moscovitz O, Tsvetkov P, Hazan N, Michaelevski I, Keisar H, Ben-Nissan G, Shaul Y, and Sharon M. A mutually inhibitory feedback loop between the 20S proteasome and its regulator, NQO1. Mol Cell 47: 76-86, 2012.

49. Olshina MA, Ben-Nissan G, and Sharon M. Functional regulation of proteins by $20 \mathrm{~S}$ proteasome proteolytic processing. Cell Cycle 17: 393-394, 2018.

50. Pickering AM and Davies KJA. Degradation of damaged proteins: the main function of the 20S proteasome. Prog Mol Biol Transl Sci 109: 227-248, 2012.

51. Reuter S, Gupta SC, Chaturvedi MM, and Aggarwal BB. Oxidative stress, inflammation, and cancer: how are they linked? Free Radic Biol Med 49: 1603-1616, 2010.

52. Richarme G, Liu C, Mihoub M, Abdallah J, Leger T, Joly N, Liebart J-C, Jurkunas UV, Nadal M, Bouloc P, Dairou J, and Lamouri A. Guanine glycation repair by DJ-1/Park7 and its bacterial homologs. Science 357: 208-211, 2017.

53. Rodrigues JV and Gomes CM. Mechanism of superoxide and hydrogen peroxide generation by human electrontransfer flavoprotein and pathological variants. Free Radic Biol Med 53: 12, 2012.

54. Saeki Y. Ubiquitin recognition by the proteasome. J Biochem 161: 113-124, 2017.

55. Salvat C, Acquaviva C, Scheffner M, Robbins I, Piechaczyk M, and Jariel-Encontre I. Molecular characterization of the thermosensitive E1 ubiquitin-activating enzyme cell mutant A31N-ts20. Eur J Biochem 267: 3712, 2000.

56. Sanchez-Lanzas R and Castano JG. Proteins directly interacting with mammalian $20 \mathrm{~S}$ proteasomal subunits and ubiquitin-independent proteasomal degradation. Biomolecules 4: 1140-1154, 2014.

57. Schaupp CM, White CC, Merrill GF, and Kavanagh TJ. Metabolism of doxorubicin to the cardiotoxic metabolite doxorubicinol is increased in a mouse model of chronic glutathione deficiency: a potential role for carbonyl reductase 3. Chem Biol Interact 234: 154-161, 2015.

58. Shang $\mathrm{F}$ and Taylor A. Ubiquitin-proteasome pathway and cellular responses to oxidative stress. Free Radic Biol Med 51: 5-16, 2011.

59. Shields DJ, Niessen S, Murphy EA, Mielgo A, Desgrosellier JS, Lau SKM, Barnes LA, Lesperance J, Bouvet M, Tarin D, Cravatt BF, and Cheresh DA. RBBP9: a tumor-associated serine hydrolase activity required for pancreatic neoplasia. Proc Natl Acad Sci U S A 107: 21892194, 2010.

60. Snyder NW, Golin-Bisello F, Gao Y, Blair IA, Freeman BA, and Wendell SG. 15-Oxoeicosatetraenoic acid is a 15hydroxyprostaglandin dehydrogenase-derived electrophilic 
mediator of inflammatory signaling pathways. Chem Biol Interact 234: 144-153, 2015.

61. Sollner S, Schober M, Wagner A, Prem A, Lorkova L, Palfey BA, Groll M, and Macheroux P. Quinone reductase acts as a redox switch of the $20 \mathrm{~S}$ yeast proteasome. EMBO Rep 10: 65-70, 2009.

62. Solomon H, Bräuning B, Fainer I, Ben-Nissan G, Rabani S, Goldfinger N, Moscovitz O, Shakked Z, Rotter V, and Sharon M. Post-translational regulation of p53 function through 20S proteasome-mediated cleavage. Cell Death Differ 24: 2187-2198, 2017.

63. Tai HH, Cho H, Tong M, and Ding Y. NAD+-linked 15hydroxyprostaglandin dehydrogenase: structure and biological functions. Curr Pharm Des 12: 955-962, 2006.

64. Tai HH, Tong M, and Ding Y. 15-hydroxyprostaglandin dehydrogenase (15-PGDH) and lung cancer. Prostaglandins Other Lipid Mediat 83: 203-208, 2007.

65. Tao S, Wang S, Moghaddam SJ, Ooi A, Chapman E, Wong PK, and Zhang DD. Oncogenic KRAS confers chemoresistance by upregulating NRF2. Cancer Res 74: 74307441, 2014.

66. Tofaris GK, Layfield R, and Spillantini MG. Alphasynuclein metabolism and aggregation is linked to ubiquitin-independent degradation by the proteasome. FEBS Lett 509: 22-26, 2001.

67. Toyoda Y, Erkut C, Pan-Montojo F, Boland S, Stewart MP, Müller DJ, Wurst W, Hyman AA, and Kurzchalia TV. Products of the Parkinson's disease-related glyoxalase DJ-1, D-lactate and glycolate, support mitochondrial membrane potential and neuronal survival. Biol Open 3: 777-784, 2014.

68. Tsvetkov P, Adamovich Y, Elliott E, and Shaul Y. E3 ligase STUB1/CHIP regulates NAD(P)H:quinone oxidoreductase 1 (NQO1) accumulation in aged brain, a process impaired in certain Alzheimer disease patients. J Biol Chem 286: 8839-8845, 2011.

69. Utecht KN and Kolesar J. Bortezomib: a novel chemotherapeutic agent for hematologic malignancies. Am J Health Syst Pharm 65: 1221-1231, 2008.

70. Van Der Lee R, Buljan M, Lang B, Weatheritt RJ, Daughdrill GW, Dunker AK, Fuxreiter M, Gough J, Gsponer J, Jones DT, Kim PM, Kriwacki RW, Oldfield CJ, Pappu RV, Tompa P, Uversky VN, Wright PE, and Babu MM. Classification of intrinsically disordered regions and proteins. Chem Rev 114: 6589-6631, 2014.

71. Wang $\mathrm{W}$ and Jaiswal AK. Nuclear factor Nrf2 and antioxidant response element regulate NRH:quinone oxidoreductase 2 (NQO2) gene expression and antioxidant induction. Free Radic Biol Med 40: 1119-1130, 2006.

72. Wang X, Chemmama IE, Yu C, Huszagh A, Xu Y, Viner R, Block SA, Cimermancic P, Rychnovsky SD, Ye Y, Sali A, and Huang L. The proteasome-interacting Ecm 29 protein disassembles the $26 \mathrm{~S}$ proteasome in response to oxidative stress. J Biol Chem 292: 16310-16320, 2017.

73. Wolf I, O’Kelly J, Rubinek T, Tong M, Nguyen A, Lin BT, Tai HH, Karlan BY, and Koeffler HP. 15-Hydroxyprostaglandin dehydrogenase is a tumor suppressor of human breast cancer. Cancer Res 66: 7818-7823, 2006.
74. Yoon M-K, Mitrea DM, Ou L, and Kriwacki RW. Cell cycle regulation by the intrinsically disordered proteins $\mathrm{p} 21$ and p27. Biochem Soc Trans 40: 981-988, 2012.

75. Zhang C, Wang H-J, Bao Q-C, Wang L, Guo T-K, Chen W-L, Xu L-L, Zhou H-S, Bian J-L, Yang Y-R, Sun $\mathrm{H}-\mathrm{P}, \mathrm{Xu} \mathrm{X}-\mathrm{L}$, and You Q-D. NRF2 promotes breast cancer cell proliferation and metastasis by increasing RhoA/ ROCK pathway signal transduction. Oncotarget 7: 7359373606, 2016.

Address correspondence to:

Prof. Michal Sharon

Department of Biomolecular

Sciences

Weizmann Institute of Science

234 Herzl Street

Rehovot 7610001

Israel

E-mail: michal.sharon@weizmann.an.il

Date of first submission to ARS Central, June 6, 2019; date of final revised submission, November 26, 2019; date of acceptance, December 13, 2019.

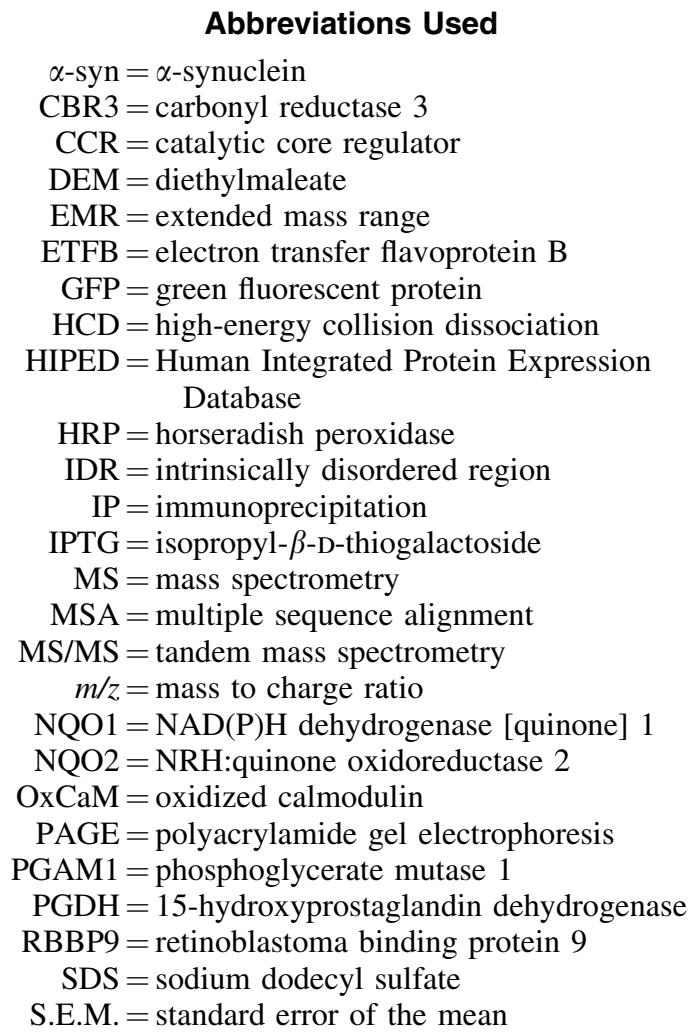

